\title{
Desarrollo sostenible y cultivo agroindustrial de la palma de aceite en Norte de Santander, Colombia
}

\author{
Dennys Jazmín Manzano López * \\ Eder Alexander Botello Sánchez ** \\ Mario de Jesús Zambrano Miranda ${ }^{* * *}$
}

Fecha de recepción: 21 de marzo de 2021

Fecha de aprobación: 28 de junio de 2021

Resumen: El cultivo agroindustrial de palma de aceite ha sido considerado en diversas partes del mundo y por varios gobiernos nacionales y regionales de Colombia como una apuesta productiva de desarrollo y competitividad. No obstante, su promoción, resultados y efectos deben ser cotejados a la luz de la nueva agenda de los Objetivos de Desarrollo Sostenible (ODS) 2030, y con ello encaminar sus principales beneficios en función del desarrollo sostenible. Con fundamento en lo anterior, la presente investigación tiene como objetivo estimar el nivel de desarrollo sostenible del cultivo agroindustrial de palma de aceite en Norte de Santander. Para ello, en primer lugar, a partir de las cuatro dimensiones del desarrollo sostenible se caracterizan las Unidades de Producción Agrícola (UPA) palmicultoras del departamento; y en segundo lugar, mediante el Índice Multidimensional de Desarrollo Sostenible (IMDS) se estima el nivel de desarrollo sostenible de cada UPA. Los resultados sugieren que la actividad no parece ofrecer condiciones que promuevan un desarrollo con crecimiento económico próspero, que sea socialmente incluyente y ambientalmente sostenible en el marco de la buena gobernanza; es decir, la actividad no promueve integralmente el desarrollo sostenible para los palmicultores de Norte de Santander.

Palabras clave: Economía agraria, agroindustria, aceite de palma, producto agrícola, desarrollo sostenible.

Clasificación JEL: O1, P28, Q01, Q56, Q57.

Cómo citar:

Manzano López, D. J. ., Botello Sanchez, E. A., \& Zambrano Miranda, M. de J. . (2021). Desarrollo sostenible y el cultivo agroindustrial de la palma de aceite en Norte de Santander, Colombia. Apuntes del Cenes, 40(72). Págs. 233 - 270. https://doi.org/10.19053/01203053.v40.n72.2021.12609

* Magíster en Economía Aplicada. Docente del Programa de Economía de la Universidad de Pamplona, Cúcuta, Colombia. dennys. manzano@unipamplona.edu.co (i) https://orcid.org/0000-0002-6181-4855

** Magíster en Estudios y Gestión del Desarrollo. Docente del Programa de Economía de la Universidad de Pamplona, Cúcuta, Colombia. alexander.botello@uniapamplona.edu.co (iD https://orcid.org/0000-0003-4363-5551 (iD http://orcid.org/0000-0003-0198-6900 Contacto de correspondencia.

*** Magíster en Gobierno y Políticas Públicas. Docente del Programa de Contaduría de la Universidad de Libre. Bogotá, Colombia. mariod. zambranom@unilibre.edu.co iD https://orcid.org/0000-0001-9730-581X 


\title{
Sustainable Development and Agro- Industrial Farming of Oil Palm in Norte de Santander, Colombia
}

\begin{abstract}
The agro-industrial farming of oil palm has been considered in various parts of the world and by several national and regional governments of Colombia, as a productive commitment to development and competitiveness. However, its promotion, results and effects must be compared in light of the 2030 Agenda for Sustainable Development Goals (SDG), and thereby direct its main benefits in terms of sustainable development. Based on the above, this research aims to estimate the level of sustainable development of the agro-industrial cultivation of oil palm in Norte de Santander. For this, first of all, from the four dimensions of sustainable development, the Agricultural Production Units (UPA, by its acronym in Spanish) of palm growers of the state are characterized; and secondly, the level of sustainable development of each UPA is estimated by the Multidimensional Index of Sustainable Development (MISD). The results suggest that the activity does not seem to offer conditions that promote development with prosperous economic growth, which could be socially inclusive and environmentally sustainable within the framework of good governance; in other words, the activity does not fully promote sustainable development for the palm growers of Norte de Santander.
\end{abstract}

Keywords: Agricultural economics, agroindustry, vegetable oils, agricultural products, sustainable development. 


\section{INTRODUCCIÓN}

En distintas regiones del mundo y a lo largo de la historia, el progreso económico y material de la sociedad se ha alcanzado paralelamente con el incremento de la desigualdad en los ingresos y las condiciones de vida de las personas. Al respecto, señala Bourguignon (2017): "La evolución de la desigualdad entre países refleja la lógica del crecimiento de la economía mundial y la forma en que ésta se extendió geográficamente" (p. 55). Asimismo, a la par de este progreso, la actividad humana parece ser la causa directa de los diversos cambios físicos que experimenta el planeta, que se traducen en importantes afectaciones ambientales. Jacobs (1991) afirma que "Vista a nivel mundial, la degradación del medio ambiente parece ser, por el contrario uno de los principales productos de la actividad económica industrializada" (p. 68). En este contexto se configura un nuevo paradigma en el que interactúan sistemas complejos, como el crecimiento económico, la inclusión social y el medio ambiente. Lo anterior ha suscitado el interés internacional por un nuevo modelo, que logre promover simultáneamente intereses aparentemente excluyentes, un modelo que en el marco de la gobernanza consiga el consenso mundial por el bienestar no solamente del planeta, sino de la humanidad tanto a nivel nacional, regional y local.

El llamado universal de la nueva Agenda Internacional 2030 de los Objetivos del Desarrollo Sostenible (ODS), que promueve de forma sinérgica el crecimiento económico, la inclusión social, el medio ambiente sostenible y la buena gobernanza, exige a los diferentes niveles de gobiernos, así como al sector privado, programas que logren no solo la transformación deseada del territorio, sino principalmente afrontar y solucionar las problemáticas multidimensionales que aquejan a las comunidades.

En ese orden de ideas, se hace necesario acudir a las capacidades endógenas de los territorios para la creación de condiciones que materialicen la prosperidad, y para hacer posible el desarrollo sostenible es imperativo que las actividades humanas sean comprendidas, abordadas e implementadas de forma 
integral, sistémica y sinérgica. Muchas de las actividades económicas que se gestan en los territorios han sido elegidas como apuestas de desarrollo, tal es el caso de la agroindustria de la palma de aceite en Norte de Santander, que en uno de los ejes temáticos de su Plan de Desarrollo "Un Norte Productivo para Todos (2016-2019)" establece el programa: "Un norte en paz, incluyente y competitivo", con lo cual se propone promover la construcción de entornos sociales vinculados a proyectos productivos con vocación agrícola y desarrollo sostenible que permitan cerrar brechas.

La palma de aceite es considerada un motor de desarrollo, dada la cantidad de hectáreas sembradas y el número de empleos que genera, lo cual representa una fuente importante de ingresos para miles de hogares rurales. Según el Plan de Desarrollo 2016-2019: "Un Norte Productivo para todos", entre los cultivos permanentes se destaca la palma de aceite, ya que durante los años 2011 al 2015 el área sembrada se duplicó:

Presentando un aumento promedio anual superior a las 3.000 hectáreas, impulso logrado principalmente al acceso a los créditos del Fondo Complementario de Garantías y la inversión privada. En esta línea de producción, participan desde grandes productores hasta pequeños campesinos, que actualmente cultivan unas 32.000 hectáreas con producciones que sobrepasan las 420.000 toneladas en racimo de fruta fresca. Este cultivo se desa- rrolla en los municipios de Cúcuta, El Zulia, La Esperanza, Sardinata y Tibú, donde el 66\% del área establecida corresponde a este último. (Gobernación de Norte de Santander, 2016, p. 24)

Según la Federación Nacional de Cultivadores de Palma de Aceite (Fedepalma, s.f.), en Norte de Santander la producción de aceite de palma crudo alcanzó las 13500 toneladas en 2015, que corresponden al $1 \%$ de la producción nacional; de igual forma, el gremio señala que, de acuerdo con datos del Sistema de Información Estadística del Sector Palmero (SISPA), a nivel departamental se cuenta con 907 palmicultores y dos núcleos palmeros en funcionamiento. Sumado a esto, en el 2016 el departamento tenía 15224 hectáreas sembradas en palma de aceite y 12880 hectáreas en producción. Lo cual significa, en términos de generación de empleo, 1903 empleos directos y 2855 empleos indirectos, para un total de 4758 empleos generados.

Así las cosas, el ejercicio de la agroindustria del cultivo de palma de aceite debe traducirse en una estrategia próspera, incluyente y sostenible, que promueva la buena gobernanza, y para ello es indispensable dilucidar los escenarios en los cuales se gesta la actividad; lo cual hace de la presente propuesta de investigación todo un desafío por la magnitud de esta, teniendo en cuenta que se debe abordar multidimensionalmente. 
Por lo anterior, el cultivo de palma de aceite es de gran importancia debido al área cultivada, la producción y el rendimiento, como también por los diversos beneficios relacionados con la movilidad social a través de los ingresos para los hogares rurales de Norte de Santander. Además, mediante la gobernanza busca potencializar y articular con el sector privado y gremios. No obstante, también es preciso no perder de vista sus efectos medioambientales $\mathrm{y}$, con mayor razón al ser considerada como una de las apuestas productivas del departamento. De modo que, teniendo en cuenta lo anterior, el presente artículo analiza con mayor detalle el contexto del cultivo agroindustrial de la palma de aceite en el departamento de Norte de Santander, a partir del siguiente interrogante transversal: ¿cuál es el nivel de desarrollo sostenible del cultivo agroindustrial de la palma de aceite en Norte de Santander?

Para responder a esta pregunta, el documento se estructura en seis secciones. La primera es esta introducción; la segunda expone los antecedentes, el estado del tema y el marco teórico de la investigación; la tercera presenta la metodología usada; la cuarta muestra los resultados obtenidos; la quinta contiene la discusión; y la sexta señala las conclusiones.

\section{ANTECEDENTES}

\section{Estado del tema}

En la literatura contemporánea relacionada con el desarrollo sostenible hay diversos enfoques teóricos, los cuales configuran constantemente el paradigma del fenómeno. Por ejemplo, la perspectiva neoaustríaca temporal propone el avance de la tecnología como característica del desarrollo sostenible, bien sea como un proceso de sustitución o para reaccionar ante las incertidumbres futuras (Gallopín, 2003). Por su parte, la teoría neoclásica-equilibrio propende al progreso de la mano del crecimiento sostenible. Está basada en la tecnología de sustitución y en la creencia de que el equilibrio optimiza las externalidades ambientales. Es decir, la tecnología supera las problemáticas ambientales.

Las dos teorías descritas por Gallopín (2003) afirman que la ciencia puede ser un instrumento idóneo para enfrentar las adversidades que se le presentan a la humanidad a medida que avanza, pero el solo hecho de mostrar la tecnología como baluarte para afrontar las adversidades no es garantía de que realmente respalde el futuro de la humanidad; es por eso que poner en marcha el desarrollo sostenible exige comprender los componentes de este, puesto que son sistemas complejos que interactúan entre sí y están asociados a la economía, la inclusión social, el medio ambiente y las revoluciones tecnológicas. 
Por tal motivo, Gallopín (2003) recomienda la medición del desarrollo sostenible mediante el uso indicadores, con el objetivo de fijar metas alcanzables. Por consiguiente, cada región podría tomar una posición diferente acerca de la problemática del desarrollo sostenible. A continuación, se describen los principales índices de desarrollo sostenible.

\section{Índices de desarrollo sostenible}

Existe abundante literatura sobre el levantamiento de información y la construcción de indicadores e índices de desarrollo sostenible. El trabajo de Arias (2006) expone los indicadores definidos a partir de diversos enfoques; por ejemplo, el punto de vista de Hartwick-Solow sobre la economía neoclásica, que aborda la sostenibilidad débil. Desde esta perspectiva se formularon indicadores como el Producto Nacional Ajustado Ambientalmente; el Índice de Bienestar Económicamente Sostenible (IBES) desarrollado por Daly y Cobb (1989); el Sistema de Cuentas Ambientales y Económicas (SCAE) de las Naciones Unidas, formulado inicialmente en 1993; y el Ahorro Neto Ajustado del Banco Mundial.

Por otra parte, el enfoque de la sostenibilidad fuerte de la economía ecológica estableció indicadores como la Huella Ecológica, propuesto por Wackernagel y Rees (1997); el Índice de Planeta Vivo, elaborado por el Fondo Mundial para la Vida Silvestre. De igual forma, en los últimos veinte años otros enfoques han contribuido al acervo de herramientas en torno al desarrollo sostenible, como el Capital Natural no Decreciente de University College London y la perspectiva del desarrollo humano de Sen (2000).

También es preciso resaltar el trabajo de Quiroga (2007), quien, al igual que Arias (2006), hace un breve recuento de los indicadores e índices, pero de forma cronológica de acuerdo con su objeto de medición, y los divide en tres generaciones: los de primera generación surgen desde 1980 y están relacionados directamente con indicadores ambientales o de sostenibilidad ambiental; los de segunda generación se presentan en 1990 y tienen una mirada multidimensional, es decir, utilizan múltiples indicadores e índices para abordar las dimensiones del desarrollo sostenible; y finalmente, los de tercera generación, que tratan de indicadores e índices transversales, sinérgicos y sistemáticos, los cuales dan cuenta del progreso, es por eso que estos índices son conocidos como de sostenibilidad o de sostenibilidad hacia el desarrollo.

El desarrollo sostenible se describe como una herramienta multidimensional de alcance global y local, que permite realizar un análisis por medio de indicadores, como lo proponen Gallopín (2013) y la Agenda 2030 de los Objetivos del Desarrollo Sostenible. En este sentido, Sachs (2014) plantea un enfoque de desarrollo sostenible basado 
en la interacción de cuatro sistemas complejos que deben ser analizados por medio de indicadores, con el fin de avanzar hacia una "buena sociedad"; asimismo, el punto de vista de Sachs (2014) es simultáneamente un concepto analítico y normativo; en el primero, como un proyecto intelectual en la medida que pretende comprender las interacciones entre tres sistemas complejos: la economía mundial, la sociedad global y el medio ambiente físico de la Tierra; el segundo concepto se debe a la recomendación de una serie de objetivos a los que el mundo debería aspirar en el marco de la gobernanza, una visión normativa en la que subsisten los valores, la visión holística de lo que compone una buena sociedad.

En ese orden de ideas, dicho enfoque tiene una estructura de cuatro pilares intrínsecamente concernidos, que interactúan como sistemas complejos: el crecimiento económico, la inclusión social, el medio ambiente sostenible y la gobernanza, donde la menor afectación de uno ellos ocasiona un cambio importante en los otros tres. Sachs (2014) afirma:

El desarrollo sostenible pretende construir un mundo donde el progreso económico esté lo más extendido posible; la pobreza extrema sea eliminada; la confianza social encuentre apoyo en políticas orientadas al refuerzo de las comunidades; y el medio ambiente esté protegido frente a degradaciones inducidas por el hombre. (p. 20)

\section{MARCO TEÓRICO}

Desde su nacimiento en los años cuarenta, la teoría económica del desarrollo se ha caracterizado por la conformación de diversas escuelas, las cuales, como señala Hidalgo-Capitán (2011), han girado en torno a la aceptación, el condicionamiento o el rechazo de dos premisas fundamentales, como la monoeconomía y el beneficio mutuo del comercio internacional. Sin embargo, paralelamente, el desarrollo se ha ido aproximando a escuelas cada vez más multidisciplinares, que cosechan los avances de otras disciplinas como la geografía, la ecología, la sociología y la antropología, entre otras; esta aproximación abandona la idea del desarrollo como sinónimo del crecimiento económico, es decir, el desarrollo como riqueza material fundamentada en la industrialización (una visión estrictamente economicista), por una que entiende al ser humano como el fin $y$ medio del mismo, lo que representa un cambio de paradigma, que es liderado por la escuela alternativa del desarrollo, la cual se ha configurado como transversal e integradora, dado que en ella concurren múltiples perspectivas como la territorial, de género, posdesarrollo, altermundialización y la sostenibilidad.

Ahora bien, el acercamiento del desarrollo a nuevas perspectivas obedece a las preocupaciones de la sociedad ante los resultados ambiguos del progreso 
económico, uno de los más sobresalientes relacionado con el medio ambiente, pues como anota Brown (1996):

Los problemas ambientales relacionados con la actividad y el crecimiento económico, han conducido a una situación, en la cual, la economía global está dañando los fundamentos en los que se sustenta. Las pruebas del deterioro de la infraestructura ecológica de la Tierra toman la forma de industrias pesqueras en declive, reducción de las capas freáticas, disminución de la extensión de bosques, erosión del suelo, desecación de lagos, olas de calor que agotan las cosechas y desaparición de especies. (p. 22)

Así, el progreso económico y el cuidado del medio ambiente se plantearon como factores indisolubles y antagónicos, en que la degradación física del planeta era el resultado inevitable del mejoramiento material de la calidad de vida en los países y un producto exclusivamente del sistema capitalista; no obstante, con la presentación internacional del desarrollo sostenible fue posible armonizar y hacer compatibles diversos objetivos, puesto que, como señala Jacobs (1991), se proclamó como la meta central de la política económica de los países. A partir de allí, pocos enfoques han logrado calar y posicionarse tan rápidamente en el lenguaje económico, político y social de la humanidad; a pesar de ello, no existe en la literatura del siglo XXI un consenso sobre sus alcances y significado, dada la complejidad y holismo del propio enfoque, no solo en lo que este puede significar desde las diversas ciencias y disciplinas, sino también en cuanto al paradigma, la filosofía y las características adjudicadas al mismo. Es por esto que la presente investigación hace una breve revisión de literatura, para la comprensión integral del marco teórico de este trabajo.

En ese orden de ideas, según Carrizosa (1996), el desarrollo sostenible ha sido el arquetipo que ha influenciado el siglo XX (y aún más el siglo XXI), cuando las corrientes que lo impulsan han sido la economía, la sociología y la política. Lo que claramente, como se mencionó en párrafos anteriores, ha producido cientos de conceptualizaciones y enfoques, y con ello controversias; una de las más discutidas y que enmarca gran parte de los referentes teóricos es el límite del crecimiento económico, que Carrizosa (1996) resume como una controversia entre los límites ecológicos y socioeconómicos, la cual ya ha sido resuelta en el plano académico con la argumentación del derecho al desarrollo, en donde el crecimiento económico es el medio y no el fin del desarrollo, lo que convierte a la población y la pobreza en temas cruciales. Esto refleja, según Carrizosa (1996), una perspectiva antropocéntrica y una visión institucionalista, toda vez que lo anterior se ha formalizado en el desarrollo tanto de la agenda pública como de múltiples indicadores. 
Por otra parte, Dixon y Fallon (1991) no se centran en las controversias, sino en los significados del desarrollo sostenible y lo que de allí se deriva como perspectivas teóricas. Estos autores identifican tres usos distintos en la conceptualización de la sostenibilidad, i) como un concepto puramente físico para un recurso individual, ii) como un concepto físico para un grupo de recursos o ecosistemas y iii) como un concepto social, físico y económico. Los autores (1991) expresan que cada significado por su cuenta no contempla la esencia del desarrollo sostenible (integralidad), dado que no son suficientes por sí solos, pues cada uno por separado afronta las adversidades de múltiples factores que componen la sociedad; además, es necesario esclarecer algunos interrogantes en estos conceptos, por tanto es indispensable ampliar el espectro explicativo a otras dimensiones. En resumen, lo sugerido por estos autores es un primer avance hacia la integralidad del desarrollo sostenible, pues contemplan la multidisciplinariedad y multidimensionalidad de este.

Sachs (1996) aborda el desarrollo sostenible contemplando el espectro que Dixon y Fallon (1991) señalan, e incorpora una problematización entre la justicia y la naturaleza, una crisis que plantea la anatomía política del desarrollo sostenible. De esta anatomía, Sachs (2014) resume tres puntos de vista: i) la fortaleza, ii) el astronauta y iii) el hogar. Con estos tres puntos de vista, este autor hace un aporte signifi- cativo, toda vez que en la perspectiva de la fortaleza señala que el desarrollo no se puede universalizar y que ello implica la zonificación del uso de los recursos de modo que se reivindique no solo el derecho al desarrollo, sino también al tipo de desarrollo; la perspectiva del astronauta sugiere el fortalecimiento de las ciencias planetarias, en donde se debe hablar de la responsabilidad global, que será conforme y proporcional al deterioro ambiental; finalmente, la perspectiva del hogar se refiere más a los lastres del desarrollo que a sus virtudes, porque el modelo imperante ha dejado atrás a miles de hogares, los cuales, lejos de disfrutar, se resisten al desarrollo; lo que nuevamente se engrana con la posibilidad de otros modelos de convivencia. Como se puede observar, en las tres perspectivas está incorporada la justicia como un elemento constitutivo del desarrollo sostenible, en donde la equidad intergeneracional e intrageneracional se plantean como horizontes.

Finalmente, otros autores, entre los que se destacan Xercavins et al. (1996), quienes construyen sobre los planteamientos de los demás autores y aportan al enfoque a partir de características propias de la naturaleza: el constante cambio; lo que muchos autores en ocasiones señalan como elementos emergentes o el principio del caos, y en ello conciben lo que, a su parecer, son los nueve principios del desarrollo sostenible: i) principios de pensamiento holístico; ii) principio de precaución; iii) 
principio de equidad intergeneracional y/o insustituibilidad y mantenibilidad y desarrollo de los capitales naturales; iv) principio de innovación y utilización de tecnologías limpias; v) principio de irreversibilidad cero; vi) principio de sostenibilidad local y/o subsidiaridad, vii) principios de sostenibilidad global y finalmente, viii) principio de calidad de vida. Los anteriores principios recogen ampliamente las discusiones, propuestas y problemáticas surgidas en torno al desarrollo sostenible, lo que los convierte en una síntesis valiosa para la literatura del fenómeno en estudio.

Sin importar la variedad de teorías y de enfoques del desarrollo sostenible, existen elementos en común en la mayor parte de las interpretaciones, un arquetipo ineludible en el que, según Jacobs (1991), Sachs (1996), Xercavins et al. (2005) y Correa (2017), prima el significado esencial. Estos autores señalan como común:

- El reconocimiento del impacto a largo plazo sobre los recursos y las restricciones ambientales del comportamiento del desarrollo y el consumo.

- El atrincheramiento de las consideraciones ambientales en la determinación de la política económica.

- El compromiso ineludible del desarrollo sostenible con la equidad y las generaciones futuras.

- Finalmente, su relación con el desarrollo, es decir, con el bienestar de las personas y del mejoramiento del medio ambiente.
Los anteriores elementos han sido cotejados desde las diversas teorías y enfoques; no obstante, con el avance de las disciplinas y la formulación de dimensiones, se han convertido en las dimensiones tradicionales de desarrollo sostenible: económica, social, ambiental y de gobernanza. Estas dimensiones, dependiendo de la perspectiva del autor, adquieren diversas denominaciones, jerarquías u órdenes de importancia.

Luego de la exposición de algunos enfoques de autores del desarrollo sostenible, la presente investigación enmarca como referente teórico a Sachs (2014), no solo por motivos teóricos (los cuales serán presentado más adelante), sino también por su labor como director del Proyecto del Milenio, asesor especial del secretario general de las Naciones Unidas sobre los ODM, y artífice de la nueva Agenda Internacional de los Objetivos del Desarrollo Sostenible (ODS) 2030 de la Organización de las Naciones Unidas (ONU), que traza las metas a todos los países del mundo y establece los objetivos por lograr como civilización humana.

\section{Desarrollo sostenible según Jeffrey Sachs}

El ser humano y su actividad, como señala Sachs (2014), han configurado una nueva era en la historia del planeta, el antropoceno, era en donde los grandes cambios físicos del planeta se deben a las acciones del ser humano, 
situación que impone nuevos retos para hacer compatibles el progreso económico y material de los países con la conservación de la Tierra. Para ello, es necesario que el desarrollo sea realmente sostenible y no solo en términos ambientales, sino que requiere de un desarrollo sinérgico con las demás dimensiones complejas que forman parte de la sociedad, como la economía, la esfera social y la gobernanza.

Sachs (2014) señala que el desarrollo sostenible es tanto un marco normativo como una ciencia en sí, un campo intelectual; como marco normativo supone el diseño de un conjunto de metas u objetivos que tengan como horizonte una sociedad deseable. En este caso, Sachs (2014) no es ajeno a los dilemas subjetivos que se derivan de dicho marco; no obstante, expresa que existen unas apuestas planetarias que hacen bien al ser humano indistintamente de su cultura o religión (estas apuestas deseables serán planteadas en cada dimensión más adelante); en cuanto al campo intelectual, afirma que el desarrollo sostenible requiere de científicos en desarrollo sostenible, teniendo en cuenta la multidisciplinariedad y la convergencia, la capacidad de estos científicos de conectar los elementos emergentes (inesperados) del constante cambio de los sistemas económico, social, ambiental y de gobernanza.

Sachs (2014) bosqueja el desarrollo sostenible como un proceso continuo sinérgico, que busca la consecución de metas y la comprensión de problemas en las cuatro dimensiones de la sociedad humana, y declara que el desarrollo sostenible es aquel que promueve el crecimiento económico sostenido, socialmente incluyente, ambientalmente sostenible y bien gobernado.

\section{Dimensiones del desarrollo sostenible}

La primera dimensión del desarrollo sostenible, pero no más importante que las demás, es la dimensión económica; en esta, el crecimiento económico se configura como el elemento indispensable para atender las necesidades materiales más apremiantes de las personas. Acabar con la pobreza y erradicar el hambre son parte de los deseos materiales de una buena sociedad, por tanto, es deseable que el progreso económico sea lo más extendido posible en la consecución del desarrollo sostenible.

Así, la dimensión económica va de la mano con la dimensión social, o de inclusión, y para ello realiza un orden lógico para la inclusión social, en donde la erradicación de la pobreza reduce las brechas sociales y la desigualdad, lo que a su vez da lugar a más y mejores oportunidades, que posibilitan la movilidad social y se traducen en el bienestar colectivo o general de la sociedad; como se observa, es deseable una sociedad sin hambre, lo que desencadena todo un círculo virtuoso. 
Sumado a lo anterior, la dimensión ambiental parte del reconocimiento de los límites planetarios y de que los principales cambios físicos de la Tierra se deben a las acciones del ser humano. El antropoceno es la era del desarrollo sostenible, cuando el cuidado del medio ambiente natural debe abandonar el crecimiento del consumo material irrestricto, en búsqueda no solo de la equidad intrageneracional, sino también de la intergeneracional.

Finalmente, las tres dimensiones mencionadas deben desenvolverse en el marco de una buena gobernanza, que es la última dimensión señalada por Sachs (2014). Él considera que la visión de una dimensión institucional (propuesta por muchos autores) deja la mayor parte de la responsabilidad del desarrollo sostenible a los Estados, invisibilizando los papeles desempeñados por el sector privado (grandes corporaciones, multinacionales) y la participación ciudadana en la construcción de sus modelos de desarrollo; pero el desarrollo sostenible no debe ignorar el alcance de muchas compañías cuya actividad influye en múltiples países; por tanto, para gobernar bien, se debe hacer de la mano de la ciudadanía, del Estado y del mercado, para que sea posible el principio de la sinergia multidimensional.

Como se puede observar, Sachs (2014) recoge tanto los avances de los autores abordados anteriormente como de otros; su enfoque es holístico, complementario, aclarador, instrumental, ampliamente profundo y ambicioso, lo que le permite a la presente investigación la identificación de variables diversas que estén relacionadas con cada dimensión expuesta.

\section{METODOLOGÍA}

La presente investigación es de tipo cuantitativo, no experimental, de corte transversal y de alcance descriptivo. La metodología se estructura en dos fases: la primera obedece a una caracterización de las Unidades de Producción Agrícola (UPA) del cultivo agroindustrial de palma de aceite a partir de las cuatro dimensiones del desarrollo sostenible; para ello, se emplean gráficos y estadísticos descriptivos de tendencia central; la segunda describe el desarrollo sostenible del cultivo agroindustrial de la palma de aceite por medio del Índice Multidimensional de Desarrollo Sostenible (IMDS).

Para lo anterior, se tomaron como fuente de información los microdatos anonimizados del 3.er Censo Nacional Agropecuario (CNA) realizado por el Departamento Administrativo Nacional de Estadística (DANE), acorde con los módulos y variables señalados en la Tabla 1, los cuales se desagregaron teniendo en cuenta las cuatro dimensiones del desarrollo sostenible. 
Tabla 1. Variables usadas para la caracterización y estimación del Índice Multidimensional de Desarrollo Sostenible

\begin{tabular}{|c|c|c|c|c|}
\hline Dimensión & $\begin{array}{l}\text { Variable de } \\
\text { primer orden }\end{array}$ & $\begin{array}{l}\text { Variable de } \\
\text { segundo orden }\end{array}$ & $\begin{array}{l}\text { Módulo capítulo } \\
\text { de información } \\
\text { en el 3.er CNA }\end{array}$ & Descripción \\
\hline \multirow{6}{*}{ 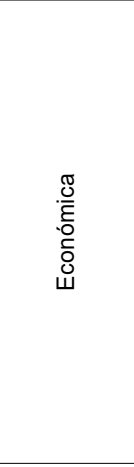 } & Producción & $\begin{array}{l}\text { Rendimiento de } \\
\text { palma por hectárea } \\
\text { sembrada }\end{array}$ & Unidad productora & $\begin{array}{l}\text { Variable cuantitativa que se obtiene de } \\
\text { la relación entre el número de toneladas } \\
\text { producidas y las hectáreas cosechadas }\end{array}$ \\
\hline & \multirow{2}{*}{ Tecnología } & Mecanización & $\begin{array}{l}\text { Máquina de uso } \\
\text { agropecuario }\end{array}$ & $\begin{array}{l}\text { Variable cualitativa que se obtiene al observar } \\
\text { la tenencia o no de determinados equipos }\end{array}$ \\
\hline & & $\begin{array}{l}\text { Modernización } \\
\text { de maquinaria }\end{array}$ & $\begin{array}{l}\text { Máquina de uso } \\
\text { agropecuario }\end{array}$ & $\begin{array}{l}\text { Variable cualitativa que se obtiene según las } \\
\text { características de los equipos a disposición }\end{array}$ \\
\hline & Infraestructura & $\begin{array}{l}\text { Construcciones } \\
\text { agropecuarias }\end{array}$ & $\begin{array}{l}\text { Construcciones de } \\
\text { uso agropecuario }\end{array}$ & $\begin{array}{l}\text { Variable cualitativa que se obtiene al observar } \\
\text { la existencia o no de construcciones }\end{array}$ \\
\hline & \multirow{2}{*}{ Empleo } & Productividad laboral & $\begin{array}{l}\text { Cultivos y unidad } \\
\text { productora }\end{array}$ & $\begin{array}{l}\text { Variable cuantitativa que se obtiene de } \\
\text { la relación entre el número de toneladas } \\
\text { producidas y el número de trabajadores }\end{array}$ \\
\hline & & $\begin{array}{l}\text { Tamaño de la } \\
\text { UPA en términos } \\
\text { del empleo }\end{array}$ & $\begin{array}{l}\text { Cultivos y unidad } \\
\text { productora }\end{array}$ & $\begin{array}{l}\text { Variable cuantitativa que se obtiene de la } \\
\text { relación entre el número de hectáreas de } \\
\text { la UPA y el número de trabajadores }\end{array}$ \\
\hline \multirow{9}{*}{$\begin{array}{l}\frac{\infty}{\pi} \\
\frac{\pi}{0} \\
\infty\end{array}$} & \multirow{3}{*}{ Educación } & Alfabetización & Personas & $\begin{array}{c}\text { Variable cualitativa que se obtiene al observar } \\
\text { si todos los miembros del hogar mayores } \\
\text { de } 15 \text { años saben o no leer y escribir }\end{array}$ \\
\hline & & Asistencia escolar & Personas & $\begin{array}{l}\text { Variable cualitativa que se obtiene al } \\
\text { observar si todos los miembros del hogar en } \\
\text { edad escolar asisten o no a la escuela }\end{array}$ \\
\hline & & Logro educativo & Personas & $\begin{array}{l}\text { Variable cualitativa que se obtiene al observar } \\
\text { si todos los miembros del hogar mayores de } \\
15 \text { año tienen o no } 9 \text { años de escolaridad }\end{array}$ \\
\hline & \multirow{2}{*}{ Vivienda } & Privación paredes & Viviendas & $\begin{array}{c}\text { Variable cualitativa que se obtiene al } \\
\text { observar si la vivienda cuenta o no con } \\
\text { paredes de determinadas características }\end{array}$ \\
\hline & & Privación pisos & Viviendas & $\begin{array}{l}\text { Variable cualitativa que se obtiene de } \\
\text { observar si la vivienda cuenta o no con } \\
\text { pisos de determinadas características }\end{array}$ \\
\hline & \multirow{3}{*}{$\begin{array}{l}\text { Acceso a } \\
\text { servicios }\end{array}$} & $\begin{array}{l}\text { Acceso a red } \\
\text { eléctrica }\end{array}$ & Viviendas & $\begin{array}{l}\text { Variable cualitativa que se obtiene al } \\
\text { observar si la vivienda cuenta o no con } \\
\text { servicios de energía eléctrica }\end{array}$ \\
\hline & & $\begin{array}{c}\text { Acceso a } \\
\text { alcantarillado }\end{array}$ & Viviendas & $\begin{array}{c}\text { Variable cualitativa que se obtiene al } \\
\text { observar si la vivienda cuenta o no } \\
\text { con servicios de alcantarillado }\end{array}$ \\
\hline & & Acceso al acueducto & Viviendas & $\begin{array}{l}\text { Variable cualitativa que se obtiene al observar si la } \\
\text { vivienda cuenta o no con servicios de acueducto }\end{array}$ \\
\hline & Salud & Cobertura en salud & Personas & $\begin{array}{l}\text { Variable cualitativa que se obtiene al } \\
\text { observar si todos los miembros del hogar } \\
\text { cuentan o no con cobertura de salud }\end{array}$ \\
\hline \multirow{5}{*}{$\begin{array}{l}\frac{\mathscr{d}}{0} \\
\frac{0}{\tilde{N}} \\
\frac{\mathscr{\omega}}{0} \\
\frac{\hat{\sigma}}{<}\end{array}$} & \multirow{2}{*}{$\begin{array}{l}\text { Desechos y } \\
\text { residuos }\end{array}$} & $\begin{array}{c}\text { Desechos animales } \\
\text { y vegetales }\end{array}$ & Unidad productora & $\begin{array}{l}\text { Variable cualitativa que se obtiene al } \\
\text { observar si la UPA realiza o no diversos } \\
\text { manejos de los desechos determinados }\end{array}$ \\
\hline & & $\begin{array}{c}\text { Desechos de } \\
\text { plástico, vidrio o PVC }\end{array}$ & Unidad productora & $\begin{array}{l}\text { Variable cualitativa que se obtiene al } \\
\text { observar si la UPA realiza o no diversos } \\
\text { manejos de los desechos determinados }\end{array}$ \\
\hline & Energía & Fuente energética & Unidad productora & $\begin{array}{l}\text { Variable cualitativa que se obtiene al observar si la } \\
\text { UPA usa o no fuentes de energías determinadas }\end{array}$ \\
\hline & \multirow[t]{2}{*}{ Agua } & $\begin{array}{l}\text { Protección fuentes } \\
\text { naturales de agua }\end{array}$ & Unidad productora & $\begin{array}{l}\text { Variable cualitativa que se obtiene al } \\
\text { observar si la UPA protege o no las } \\
\text { diversas fuentes naturales de agua }\end{array}$ \\
\hline & & $\begin{array}{c}\text { Sistema eficiente } \\
\text { de riego }\end{array}$ & Unidad productora & $\begin{array}{l}\text { Variable cualitativa que se obtiene al observar si } \\
\text { la UPA usa o no determinados sistemas de riego }\end{array}$ \\
\hline
\end{tabular}


Continuación Tabla 2

\begin{tabular}{|c|c|c|c|c|}
\hline Dimensión & $\begin{array}{c}\text { Variable de } \\
\text { primer orden }\end{array}$ & $\begin{array}{c}\text { Variable de } \\
\text { segundo orden }\end{array}$ & $\begin{array}{l}\text { Módulo capítulo } \\
\text { de información } \\
\text { en el 3.er CNA }\end{array}$ & Descripción \\
\hline & \multirow{3}{*}{ Suelos } & $\begin{array}{l}\text { Conservación } \\
\text { del suelo }\end{array}$ & Unidad productora & $\begin{array}{l}\text { Variable cualitativa que se obtiene al } \\
\text { observar si la UPA realiza determinadas } \\
\text { prácticas de conservación del suelo }\end{array}$ \\
\hline & & $\begin{array}{l}\text { Mejoramiento } \\
\text { del suelo }\end{array}$ & Unidad productora & $\begin{array}{l}\text { Variable cualitativa que se obtiene al } \\
\text { observar si la UPA realiza determinadas } \\
\text { prácticas de mejoramiento del suelo }\end{array}$ \\
\hline & & Control de plagas & Unidad productora & $\begin{array}{c}\text { Variable cualitativa que se obtiene al } \\
\text { observar si la UPA realiza determinadas } \\
\text { prácticas de control de plagas }\end{array}$ \\
\hline \multirow{5}{*}{$\begin{array}{l}\stackrel{\mathbb{N}}{N} \\
\stackrel{0}{\mathbb{N}} \\
\stackrel{5}{0} \\
\stackrel{0}{0} \\
0\end{array}$} & \multirow{3}{*}{$\begin{array}{l}\text { Papel del } \\
\text { Gobierno }\end{array}$} & $\begin{array}{l}\text { Dificultad en el } \\
\text { acceso al agua }\end{array}$ & Unidad productora & $\begin{array}{c}\text { Variable cualitativa que se obtiene al observar } \\
\text { si la UPA ha tenido o no dificultades en el } \\
\text { uso del agua por determinadas causas }\end{array}$ \\
\hline & & Asociaciones & Unidad productora & $\begin{array}{l}\text { Variable cualitativa que se obtiene al observar si } \\
\text { la UPA se ha asociado o no a alguna determinada } \\
\text { organización para el desarrollo de su actividad }\end{array}$ \\
\hline & & $\begin{array}{c}\text { Asesorías para } \\
\text { el desarrollo de } \\
\text { la actividad }\end{array}$ & Unidad productora & $\begin{array}{c}\text { Variable cualitativa que se obtiene al } \\
\text { observar si la UPA ha recibido o no asesorías } \\
\text { para el desarrollo de su actividad }\end{array}$ \\
\hline & $\begin{array}{l}\text { Vínculos con } \\
\text { el mercado }\end{array}$ & $\begin{array}{l}\text { Acceso al sistema } \\
\text { financiero }\end{array}$ & Unidad productora & $\begin{array}{l}\text { Variable cualitativa que se obtiene al } \\
\text { observar si la UPA ha solicitado o no } \\
\text { financiación para el desarrollo de la } \\
\text { actividad y si esta ha sido aprobada o no }\end{array}$ \\
\hline & Capital social & Trabajo colectivo & Unidad productora & $\begin{array}{l}\text { Variable cualitativa que se obtiene al observar } \\
\text { si la UPA ha realizado o no algún determinado } \\
\text { trabajo colectivo para el desarrollo de su actividad }\end{array}$ \\
\hline
\end{tabular}

Fuente: elaboración propia.

Las variables detalladas en la tabla anterior fueron utilizadas para la construcción del Índice Multidimensional de Desarrollo Sostenible (IMDS), el cual se definió como un índice de ponderaciones de distribución uniforme, cuya unidad de análisis son las UPA del cultivo agroindustrial de la palma de aceite en Norte de Santander. En este sentido, el IMDS estima el nivel de desarrollo sostenible para cada UPA del cultivo agroindustrial de la palma de aceite en Norte de Santander, a partir de las cuatro dimensiones del desarrollo sostenible $\left(D_{i}\right)$, cuya expresión es:

$$
I M D S_{i}=\sum_{i=1}^{4} 0,25 D_{i}
$$

Donde $D_{l}$ es la dimensión económica, $D_{2}$ es la dimensión de la inclusión social, $D_{3}$ es la dimensión ambiental y $D_{4}$ es la dimensión de la gobernanza. Ahora bien, la valoración de cada dimensión se estima de la siguiente forma:

$$
D_{i}=\sum_{j=1}^{n} \frac{1}{n}\left(\operatorname{Var} 1_{j}\right)
$$


Donde $D_{i}$ es el valor agregado de la dimensión $i, n$ representan la cantidad de variables $j$ que componen la dimensión $i$, $\operatorname{Varl}_{\mathrm{j}}$ es el valor agregado de la variable $j$ de primer orden relacionada con la dimensión $i$. De igual forma, se tiene que

$$
\operatorname{Var} 1_{j}=\sum_{k=1}^{m} \frac{1}{m}\left(\operatorname{Var} 2_{k}\right)
$$

Donde $\operatorname{Var}_{\mathrm{j}}$ es el valor agregado de la variable $j$ de primer orden, $m$ representa la cantidad de variables $k$ que componen la variable $j$ de primer orden, $y$ $\operatorname{Var} 2_{\mathrm{k}}$ es la calificación de la variable $k$ de segundo orden relacionada con la variable $j$ de primer orden.

La variable $\operatorname{Var} 2_{\mathrm{k}}$ es la calificación de cada una de las variables $k$ de segundo orden, la cuales se encuentran definidas en una escala de 0 a 100 dependiendo de la relación favorable con el desarrollo sostenible.

\section{RESULTADOS}

Caracterización de las Unidades de Producción Agrícola del cultivo agroindustrial de la palma de aceite en Norte de Santander

En el cultivo de palma de aceite, según el Tercer Censo Nacional Agropecuario (3.er CNA) (DANE, 2014), a nivel nacional se registraron 20040 Unidades Productoras Agropecuarias (UPA), de las cuales Norte de Santander concentra el $2.3 \%$, lo que indica un total de 458 UPA, que representan el $0.75 \%$ del total de UPA en el departamento. La información reporta 458 UPA palmicultoras en Norte de Santander; no obstante, se encontraron 124 unidades no habitadas, por lo cual no fueron tomadas en cuenta en la presente caracterización, dado que la relación del ser humano con su entorno es un elemento fundamental para el desarrollo sostenible y, para este caso, en algunas variables las UPA no habitadas no dispondrán de información. Lo anterior deja un saldo de 334 aptas para la caracterización.

\section{Dimensión económica}

Un buen desempeño económico es indispensable para el mejoramiento del bienestar de la sociedad, puesto que permite mejorar la percepción de ingresos y, con ello, ampliar la capacidad para satisfacer las necesidades de la población. En este sentido, la importancia económica de una actividad está estrechamente ligada a su productividad y a los elementos que la determinan, como la tecnología y la infraestructura.

En lo relativo al área sembrada de palma de aceite, según datos del 3.er CNA, el departamento tiene una participación del $3 \%$ del total nacional; internamente es el tercer cultivo de mayor siembra en esta zona, después del arroz y el café, lo que representa el $6.9 \%$ del área sembrada en Norte 
de Santander y es una muestra de la importancia de la actividad para este departamento. Asimismo, del total de producción nacional de palma, el departamento aporta el $2.4 \%$, y en el interior de este, el cultivo refleja el $2.9 \%$ del total de producción agrícola. Por otra parte, el cultivo de palma en Norte de
Santander presenta un rendimiento promedio de 1,7 toneladas por hectárea sembrada y ocupa, según rendimiento, el puesto 19 de los 21 departamentos productores de palma a nivel nacional, lo cual refleja la baja productividad de las UPA; es de resaltar que cada UPA tiene en promedio 31,3 hectáreas.

Tabla 2. Variables relacionadas con la dimensión económica

\begin{tabular}{|c|c|c|}
\hline Variable & Calificación & ncia \\
\hline \multirow{3}{*}{$\begin{array}{l}\text { Rendimiento } \\
\text { de palma } \\
\text { por hectárea } \\
\text { sembrada }\end{array}$} & $\begin{array}{l}\text { Rendimiento por encima del comportamiento normal } 1 \text { de } \\
\text { los diez municipios de mayor producción en el país }\end{array}$ & $66.8 \%$ \\
\hline & $\begin{array}{l}\text { Rendimiento dentro del comportamiento normal de los } \\
\text { diez municipios de mayor producción en el país }\end{array}$ & $2.4 \%$ \\
\hline & $\begin{array}{l}\text { Rendimiento por debajo del comportamiento normal de } \\
\text { los diez municipios de mayor producción en el país }\end{array}$ & $30.8 \%$ \\
\hline \multirow{3}{*}{ Mecanización } & La UPA posee algún equipo como un tractor & $5.4 \%$ \\
\hline & $\begin{array}{l}\text { La UPA posee algún equipo como fumigadora de motor, } \\
\text { guadañadora de motor, motosierra, picadora de pastos, } \\
\text { implementos para labranza, siembra y cosecha }\end{array}$ & $25.7 \%$ \\
\hline & La UPA no posee ningún equipo de los mencionados & $68.9 \%$ \\
\hline \multirow{3}{*}{$\begin{array}{l}\text { Modernización } \\
\text { de maquinaria }\end{array}$} & $\begin{array}{c}\text { La UPA posee algún equipo como un tractor con } \\
\text { una antigüedad menor o igual a cinco años }\end{array}$ & $3.0 \%$ \\
\hline & $\begin{array}{l}\text { La UPA posee algún equipo como fumigadora de motor, guadañadora } \\
\text { de motor, motosierra, picadora de pastos, implementos para labranza, } \\
\text { siembra y cosecha con una antigüedad menor o igual a cinco años }\end{array}$ & $18.9 \%$ \\
\hline & $\begin{array}{l}\text { La UPA posee alguno de los equipos mencionados con una antigüedad } \\
\text { mayor a cinco años o no cuenta con ningún equipo de los mencionados }\end{array}$ & $78.1 \%$ \\
\hline \multirow[t]{2}{*}{$\begin{array}{l}\text { Construcciones } \\
\text { agropecuarias }\end{array}$} & $\begin{array}{l}\text { La UPA tiene alguna de las siguientes construcciones: galpón, área } \\
\text { de almacenamiento de agroinsumos, productos y agua, vivero, } \\
\text { campamentos, estanque en uso, garaje, canal de distribución de agua }\end{array}$ & $2.4 \%$ \\
\hline & La UPA no tiene ninguna de las construcciones mencionadas & $97.6 \%$ \\
\hline \multirow{2}{*}{$\begin{array}{l}\text { Productividad } \\
\quad \text { laboral }\end{array}$} & $\begin{array}{l}\text { La UPA está igual o por encima de la media de la } \\
\text { productividad laboral del departamento }\end{array}$ & $30.8 \%$ \\
\hline & $\begin{array}{l}\text { La UPA se encuentra por debajo de la media de la } \\
\text { productividad laboral del departamento }\end{array}$ & $69.2 \%$ \\
\hline \multirow{2}{*}{$\begin{array}{l}\text { Tamaño de } \\
\text { la UPA en } \\
\text { términos del } \\
\quad \text { empleo }\end{array}$} & $\begin{array}{l}\text { La UPA está igual o por encima del tamaño promedio } \\
\text { del departamento en términos de empleo }\end{array}$ & $91.3 \%$ \\
\hline & $\begin{array}{l}\text { La UPA está por debajo del tamaño promedio del } \\
\text { departamento en términos de empleo }\end{array}$ & $8.7 \%$ \\
\hline
\end{tabular}

Fuente: elaboración propia.

\footnotetext{
1 Intervalo entre el promedio de rendimiento de los diez municipios de mayor producción en el país más y menos una desviación estándar.
} 
La mecanización de los procesos productivos tiene una incidencia directa sobre la productividad de las UPA, pues la utilización de maquinaria facilita las distintas etapas del proceso de producción. Dentro de la maquinaria más utilizada por las UPA se encuentran el tractor, la fumigadora de motor, la guadañadora de motor, la motosierra, la picadora de pastos y los implementos para labranza, siembra y cosecha; sin embargo, el $68.9 \%$ de las UPA no utiliza ninguna de las máquinas mencionadas, lo que evidencia la escasa tecnificación del cultivo de palma. No obstante, hay que resaltar que del $31.1 \%$ de las UPA que poseen por lo menos alguna máquina, el $70.2 \%$ cuenta con al menos una máquina con menos de cinco años de antigüedad, lo cual es muestra de un esfuerzo de modernización de los palmicultores.

Respecto a la utilización de infraestructura en el cultivo de palma, las construcciones mínimas necesarias para garantizar un adecuado rendimiento del cultivo son galpón, área de almacenamiento de agroinsumos, productos y agua, vivero, campamentos, estanque en uso, garaje, canal de distribución de agua. Sin embargo, el $97.6 \%$ de las UPA no presenta ninguna de las construcciones mencionadas, lo cual evidencia una significativa falta de adecuación del predio para el cultivo.
Un aspecto de gran relevancia en el desempeño económico de una actividad es la capacidad de generar empleo $y$, en este sentido, el cultivo de palma en Norte de Santander provee $966^{2}$ empleos permanentes, es decir, en promedio cada UPA brinda 2,8 empleos permanentes; por otra parte, el $38.3 \%$ de las UPA genera más de dos empleos permanentes. Frente a la productividad laboral, en promedio cada trabajador permanente produce 13,0 toneladas; sin embargo, el $71.2 \%$ de las UPA se encuentra por debajo de este promedio, debido a que existen algunos casos atípicos con productividades que logran máximos de 324,1 toneladas por trabajador.

\section{Dimensión de inclusión social}

En la dimensión de inclusión social se incluyeron las variables de educación, vivienda, salud y acceso a servicios domiciliarios, y se encontró que de las 334 UPA palmicultoras del departamento, el $24.6 \%$ señala que al menos una persona es analfabeta, dato preocupante pues el departamento tiene cifras en promedio de $12.9 \%$ (DANE, 2018) (ver Tabla 3). Por otra parte, el $90.4 \%$ de las UPA tienen a los niños y jóvenes en edad escolar asistiendo efectivamente al sistema educativo, cifra que evidencia una cobertura significativa; no obstante, el logro educativo promedio es bastante bajo, dado que el $94.6 \%$ de los mayores de 15 años no superan los nueve años de escolaridad.

\footnotetext{
2 La cifra de empleo sube a 1555 empleos permanentes, teniendo en cuenta las UPA no habitadas.
} 
Tabla 3. Variables relacionadas con la dimensión de inclusión social

\begin{tabular}{|c|c|c|}
\hline Variable & Calificación & Frecuencia \\
\hline \multirow{2}{*}{ Alfabetización } & Todos los miembros del hogar mayores de15 años saben leer y escribir & $75.4 \%$ \\
\hline & Algún miembro del hogar mayor de 15 años no sabe leer y escribir & $24.6 \%$ \\
\hline \multirow{2}{*}{$\begin{array}{l}\text { Asistencia } \\
\text { escolar }\end{array}$} & Todos los miembros del hogar en edad escolar asisten a la escuela & $90.4 \%$ \\
\hline & Algún miembro del hogar en edad escolar no asiste a la escuela & $9.6 \%$ \\
\hline \multirow{2}{*}{ Logro educativo } & $\begin{array}{l}\text { Todos los miembros del hogar mayores de } 15 \text { años } \\
\text { tienen } 9 \text { años o más de escolaridad }\end{array}$ & $5.4 \%$ \\
\hline & $\begin{array}{l}\text { Algún miembro del hogar mayor de } 15 \text { años tiene } \\
\text { menos de } 9 \text { años de escolaridad }\end{array}$ & $94.6 \%$ \\
\hline \multirow{2}{*}{$\begin{array}{l}\text { Privación } \\
\text { paredes }\end{array}$} & $\begin{array}{l}\text { El material predominante de las paredes exteriores de la vivienda } \\
\text { es de bloque, ladrillo, piedra, madera pulida, tapia pisada, adobe, } \\
\text { bahareque, madera burda, tabla, tablón, material prefabricado }\end{array}$ & $95.5 \%$ \\
\hline & $\begin{array}{l}\text { El material predominante de las paredes exteriores de la vivienda } \\
\text { es guadua, palma, esterilla, otros vegetales, zinc, teja, cartón, } \\
\text { latas, desechos, plásticos, sin paredes, sin información }\end{array}$ & $4.5 \%$ \\
\hline \multirow{2}{*}{ Privación pisos } & El material predominante de los pisos de la vivienda no es de tierra, arena & $78.7 \%$ \\
\hline & El material predominante de los pisos de la vivienda es de tierra, arena & $21.3 \%$ \\
\hline \multirow{2}{*}{$\begin{array}{l}\text { Acceso a red } \\
\text { eléctrica }\end{array}$} & $\begin{array}{l}\text { La vivienda cuenta con servicios públicos, privados } \\
\text { o comunales de energía eléctrica }\end{array}$ & $86.8 \%$ \\
\hline & $\begin{array}{l}\text { La vivienda no cuenta con servicios públicos, } \\
\text { privados o comunales de energía eléctrica }\end{array}$ & $13.2 \%$ \\
\hline \multirow{2}{*}{$\begin{array}{l}\text { Acceso a } \\
\text { alcantarillado }\end{array}$} & $\begin{array}{l}\text { La vivienda cuenta con servicios públicos, } \\
\text { privados o comunales de alcantarillado }\end{array}$ & $5.1 \%$ \\
\hline & $\begin{array}{l}\text { La vivienda no cuenta con servicios públicos, } \\
\text { privados o comunales de alcantarillado }\end{array}$ & $94.9 \%$ \\
\hline \multirow{2}{*}{$\begin{array}{l}\text { Acceso al } \\
\text { acueducto }\end{array}$} & $\begin{array}{l}\text { La vivienda cuenta con servicios públicos, } \\
\text { privados o comunales de acueducto }\end{array}$ & $7.5 \%$ \\
\hline & $\begin{array}{l}\text { La vivienda no cuenta con servicios públicos, } \\
\text { privados o comunales de acueducto }\end{array}$ & $92.5 \%$ \\
\hline \multirow{2}{*}{ Cobertura } & Todos los miembros del hogar se encuentran con cobertura de salud & $81.4 \%$ \\
\hline & Algún miembro del hogar se encuentra sin cobertura de salud & $18.6 \%$ \\
\hline
\end{tabular}

Fuente: elaboración propia.

Respecto a las características de la vivienda relacionadas con las condiciones materiales de los pisos y paredes y el acceso a servicios, se observa una privación relativamente baja en el material predominante de paredes, pues solo el $4.5 \%$ posee viviendas con paredes de guadua, palma esterilla, otros vege- tales, zinc, teja, cartón, latas, desechos, plásticos o se encuentran sin paredes. En cuanto al material predominante de los pisos, el $21.2 \%$ de las UPA evidencian viviendas con pisos de tierra o arena. Frente al acceso a servicios de electricidad, alcantarillado y acueducto, la mayor dificultad se encuentra en 
alcantarillado y acueducto, teniendo en cuenta que el $94.9 \%$ y el $92.5 \%$ respectivamente, no cuenta con este servicio, lo cual puede tener repercusiones directas sobre la salud de los habitantes de las UPA palmicultoras.

Finalmente, en la dimensión de inclusión social es de resaltar que en el $81.4 \%$ de las UPA palmicultoras todos los miembros del hogar poseen cobertura en salud, lo que implica que todas las personas pertenecientes a estas unidades pueden acceder a atención médica. Pese a ello, es necesario ampliar los esfuerzos para mejorar la cobertura en salud y disminuir la brecha con las coberturas urbanas, que son cercanas al $100 \%$.

\section{Dimensión ambiental}

Respecto a la dimensión ambiental, la Tabla 4 detalla las principales características según las variables analizadas. Se observa que el $69.2 \%$ de las UPA palmicultoras no realiza manejo de desechos, lo cual implica un desaprovechamiento de los residuos orgánicos y un mayor impacto de estos en el ambiente, de allí la importancia de una disposición adecuada. Por otra parte, el $86.8 \%$ de los palmicultores manifiesta realizar algún manejo, reutilización o eliminación de desechos de plástico, vidrio o $\mathrm{PVC}$, de los productos utilizados en las actividades; sin embargo, la quema o entierre (41.6\%), que es una práctica altamente contaminante, sigue siendo bastante frecuente.

Tabla 4. Variables relacionadas con la dimensión ambiental

\begin{tabular}{|c|c|c|}
\hline Variable & Descripción & Frecuencia \\
\hline \multirow{3}{*}{$\begin{array}{c}\text { Manejo, reutilización } \\
\text { o eliminación de los } \\
\text { desechos animales } \\
\text { y vegetales }\end{array}$} & $\begin{array}{l}\text { Los envía a lagunas de sedimentación, los envía a lagunas de } \\
\text { oxidación, los envía a lagunas de lodos activados, los envía } \\
\text { a biofiltros, los envía a estercolero, los envía a compostera, } \\
\text { los envía a lombricultivo, los envía a biodigestor, los usa para } \\
\text { fertilización de suelos, los usa para alimentación animal. }\end{array}$ & $24.6 \%$ \\
\hline & $\begin{array}{l}\text { Los envía a hornos de incineración, los usa como combustible, } \\
\text { entrega al servicio de recolección, los regala, los vende. }\end{array}$ & $6.3 \%$ \\
\hline & Los dispone en río, quebrada o corriente; no maneja desechos. & $69.2 \%$ \\
\hline \multirow{3}{*}{$\begin{array}{c}\text { Manejo, reutilización } \\
\text { o eliminación de los } \\
\text { desechos de plástico, } \\
\text { vidrio o PVC }\end{array}$} & Lo reutiliza. & $45.2 \%$ \\
\hline & $\begin{array}{l}\text { Los quema o entierra, los envía a servicio de recolección, } \\
\text { los dispone en otro predio, los vende o los regala. }\end{array}$ & $41.6 \%$ \\
\hline & $\begin{array}{l}\text { Los dispone en río, quebrada, caño o manantial; no maneja ni } \\
\text { reutiliza ni elimina los desechos de plástico vidrio o PVC. }\end{array}$ & $13.2 \%$ \\
\hline \multirow{3}{*}{ Tipo de energía utilizada } & Molino de viento o eólica, panel solar, & $5,1 \%$ \\
\hline & $\begin{array}{l}\text { Red eléctrica, planta eléctrica, quema de } \\
\text { materiales y residuos vegetales, biogás. }\end{array}$ & $64.4 \%$ \\
\hline & $\begin{array}{l}\text { Combustible (gasolina, ACPM, gas), carbón mineral, tracción } \\
\text { y transporte animal; no usa ninguna fuente de energía. }\end{array}$ & $30.5 \%$ \\
\hline
\end{tabular}


Continuación Tabla 4

\begin{tabular}{|c|c|c|}
\hline Variable & Descripción & Frecuencia \\
\hline \multirow{3}{*}{$\begin{array}{l}\text { Protección de las } \\
\text { fuentes naturales } \\
\text { de agua }\end{array}$} & $\begin{array}{l}\text { Conservación de la vegetación, plantación de árboles, manejo } \\
\text { de las rondas (aislamiento, encerramiento, manto) }\end{array}$ & $79.3 \%$ \\
\hline & Reutilización del agua, tratamiento de las aguas residuales. & $0,3 \%$ \\
\hline & Rezos, manejo de sitios sagrados, ritos, pagamentos, no se protegen. & $20.4 \%$ \\
\hline \multirow{3}{*}{$\begin{array}{l}\text { Tipo de sistema de } \\
\text { riego utilizado }\end{array}$} & Goteo. & $1.2 \%$ \\
\hline & Aspersión, gravedad, no utiliza. & $98.5 \%$ \\
\hline & Bombeo manual o por mateo. & $0.3 \%$ \\
\hline \multirow[t]{2}{*}{$\begin{array}{l}\text { Prácticas de } \\
\text { conservación de suelos }\end{array}$} & $\begin{array}{l}\text { Siembra directa o siembra manual, rotación de cultivos, labranza } \\
\text { mínima, siembra de coberturas vegetales, prácticas de conservación } \\
\text { (terrazas, acequias, zanjillas, jarillones, muros o gaviones de contención, } \\
\text { otros); elaboración de sustratos de suelos, enrastrojamiento. }\end{array}$ & $65.9 \%$ \\
\hline & Rezos, ritos, pagamentos, no utiliza. & $34.1 \%$ \\
\hline \multirow{3}{*}{ Mejoramiento del suelo } & Fertilizante orgánico, enmienda o corrector de acidez de suelos. & $41.9 \%$ \\
\hline & Fertilizante químico, quemas. & $19.8 \%$ \\
\hline & Rezos, ritos, pagamentos, no utilizó. & $38.3 \%$ \\
\hline \multirow{3}{*}{$\begin{array}{l}\text { Control de } \\
\text { plagas, malezas y } \\
\text { enfermedades }\end{array}$} & Control orgánico, llantas repelentes o atrayentes. & $20.4 \%$ \\
\hline & $\begin{array}{l}\text { Control manual, control mecanizado, control biológico, } \\
\text { plantas genéticamente modificadas. }\end{array}$ & $36.5 \%$ \\
\hline & Control químico, rezos, ritos, pagamentos. & $43.1 \%$ \\
\hline
\end{tabular}

Fuente: elaboración propia.

Se observa que el $30.5 \%$ de las UPA con cultivos de palma de Norte de Santander usan combustible, carbón mineral, tracción y transporte animal o no usan ninguna fuente de energía, lo cual es desfavorable tanto en términos ambientales como en términos de la eficiencia energética. Al respecto, vale traer a colación lo expuesto por Huerga et al. (2011), quienes afirman que

[el] cambio de la tracción animal a la mecánica trajo múltiples discusiones en cuanto a las ventajas que uno y otro sistema planteaban. Algunos autores sostienen que la tracción mecánica es un avance tecnológico ya que permite aumentar los rindes en las tierras y disminuir los tiempos de trabajo (Frank 1977; Rydberg T. y Jansén J. 2002). Otros mencionan que la tracción animal presenta mayores ventajas desde el punto de vista ecológico y energético (Galindo 2002; Toledo 2002). (Huerga et al., 2011, p. 1)

Concretamente en combustibles, Ferrís y Tovar (2012) señalan que, desde el punto de vista energético, se puede definir la agricultura convencional como el uso de la tierra para transformar petróleo en alimentos, con un balance energético negativo de siete calorías invertidas para una caloría de alimento; 
no obstante, Huerga et al. (2011) expresan que, en el uso de animales "A diferencia de la tracción mecánica, es mucho más limitada la posibilidad de incrementar la potencia. Para ello, se recurre a aumentar el número de animales y cubrir la demanda requerida por el implemento" (p. 4). Lo anterior hace más complejo el ejercicio operativo de la agricultura y, aún más, si no se hace uso de ninguna fuente de energía; por tanto, dichas fuentes evidencian tanto pros como contras para el desarrollo sostenible en términos del cuidado del medio ambiente, como también en la productividad y eficiencia energética.

Por otra parte, teniendo en cuenta que el agua no es solo un recurso fundamental en la producción agrícola, sino que también significa un engranaje social indispensable, se percibe el interés de los palmicultores por cuidar o proteger las fuentes naturales del recurso hídrico, puesto que el 79.3\% de las UPA señalan que realizan alguna actividad de protección. De igual forma, el interés por cuidar o proteger el recurso hídrico puede notarse, en parte, por los diversos sistemas de riego utilizados; sin embargo, solo el $1.2 \%$ utiliza sistema de riego eficiente como el de goteo.

La calidad de los suelos es fundamental para toda actividad agrícola, por ello se deben conservar, así como emplear prácticas de mejoramiento y controles de plagas amables con el ambiente. En este sentido, el $65.9 \%$ de los palmicultores manifestaron realizar al menos una práctica para la conservación de sus suelos; respecto a las prácticas de mejoramiento de suelos, la más utilizada es la de fertilizante orgánico y la corrección de acidez de suelos (41.9\%); asimismo, el $56.9 \%$ efectúa controles de plagas, como el control orgánico, manual, mecanizado y biológico, que no son tan nocivos para el medio ambiente.

Lo anterior implica un reto para la producción de palma sostenible y amigable con el medio ambiente, tal como lo señalan Sanjuán y Moreno (2010). Por eso es necesario lograr que las prácticas agrícolas mejoren su productividad, para que se pueda cumplir con la meta de alimentar a miles de millones de personas en el mundo sin deteriorar los suelos, lo cual es posible gracias a la biotecnología y al uso de microorganismos.

\section{Dimensión de gobernanza}

Finalmente, en la dimensión de gobernanza se analizó el papel del Gobierno, como el encargado de garantizar las condiciones que permitan el pleno desarrollo de la actividad agrícola; así como también el papel de las mismas empresas o en este caso de las unidades productivas, para promover conexiones y redes entre actores. En este sentido, el acceso al agua es un elemento fundamental, en donde 
solamente el $3.3 \%$ de las UPA manifestaron haber tenido dificultades por restricción por parte de instituciones, personas particulares o por la ausencia de infraestructura (ver Tabla 5).

Tabla 5. Variables relacionadas con la dimensión de gobernanza

\begin{tabular}{|c|c|c|}
\hline Variable & Descripción & Frecuencia \\
\hline \multirow[b]{2}{*}{$\begin{array}{l}\text { Dificultad en el } \\
\text { acceso al agua }\end{array}$} & No ha tenido dificultades & $96.7 \%$ \\
\hline & $\begin{array}{l}\text { Ha tenido dificultades en el uso del agua por } \\
\text { restricción por parte de instituciones o personas } \\
\text { particulares o porque no hay infraestructura }\end{array}$ & $3.3 \%$ \\
\hline \multirow[t]{2}{*}{ Asociaciones } & $\begin{array}{c}\text { Pertenece por lo menos a alguna: cooperativa, gremios, } \\
\text { asociaciones de productores, centros de investigación, } \\
\text { organizaciones comunitarias (consejo comunitario, asociación } \\
\text { de cabildos, de mujeres, de ancianos o de jóvenes) }\end{array}$ & $52.1 \%$ \\
\hline & No pertenece a ninguna asociación, no sabe, no responde & $47.9 \%$ \\
\hline \multirow{2}{*}{ Asesorías } & Recibió asistencia o asesoría & $35.3 \%$ \\
\hline & No recibió asistencia o asesoría & $64.7 \%$ \\
\hline \multirow{3}{*}{ Acceso al sistema financiero } & Solicitó crédito o financiación y fue aprobado & $97.9 \%$ \\
\hline & Solicitó crédito o financiación y no fue aprobado & $2.1 \%$ \\
\hline & No solicitó crédito o financiación & $0.0 \%$ \\
\hline \multirow{2}{*}{$\begin{array}{l}\text { Trabajo colectivo (minga, } \\
\text { mamuncia, convite, } \\
\text { Yanama, mano voltiada, } \\
\text { get together, etc.) }\end{array}$} & Hizo trabajo colectivo durante los últimos 30 días & $8.4 \%$ \\
\hline & No hizo trabajo colectivo durante los últimos 30 días & $91.6 \%$ \\
\hline
\end{tabular}

Fuente: elaboración propia.

Por otra parte, el sector palmicultor es reconocido por ser uno de los más organizados en el país. Tiene un gremio a nivel nacional llamado Fedepalma. Los resultados señalan que el $52.1 \%$ pertenece a alguna cooperativa, gremio o asociación; no obstante, aún es significativo el número de UPA que han decidido trabajar sin apoyo del gremio o de alguna colectividad. En cuanto al trabajo colectivo entre los palmicultores, las cifras son muy reveladoras, puesto que solo el $8.4 \%$ de las UPA han trabajado de alguna forma colectiva como minga, mamuncia, convite, Yanama, "mano voltiada", get together, etc; lo cual genera una barrera para ampliar la capacidad productiva y compartir experiencias que multipliquen las oportunidades y potencialidades del cultivo.

Las actividades agrícolas y su producción están pensadas no para el autoabastecimiento, sino para su mercantilización, lo que hace necesaria la producción a escala, que requiere financiación, de allí la importancia de tener acceso al sistema financiero. En el caso de las UPA palmicultoras, el $100 \%$ ha acudido al sistema financiero para solicitar crédito, de este porcentaje, al 
$97.9 \%$ le fue aprobado, lo cual evidencia el fuerte apalancamiento financiero que ha tenido la actividad.

\section{IMDS de las UPA con cultivo de palma de aceite en Norte de Santander}

El promedio de las calificaciones de IMDS de las UPA palmicultoras de Norte de Santander fue de 48,04 puntos de 100 posibles, cifra poco alentadora si se tiene en cuenta que gran parte de las UPA no logra llegar al punto centro de la distribución del índice de 50 puntos; además, el $48.8 \%$ de las UPA no alcanzó la calificación promedio. Asimismo, al observar la distribución de la calificación cuantitativa del IMDS en la Figura 1, se puede apreciar cómo la mayoría de las UPA (71\%) se concentran en las calificaciones de entre 41,6 y $54,5^{3}$ puntos, con una máxima calificación de 67,7 y un mínimo de 26,7 puntos.

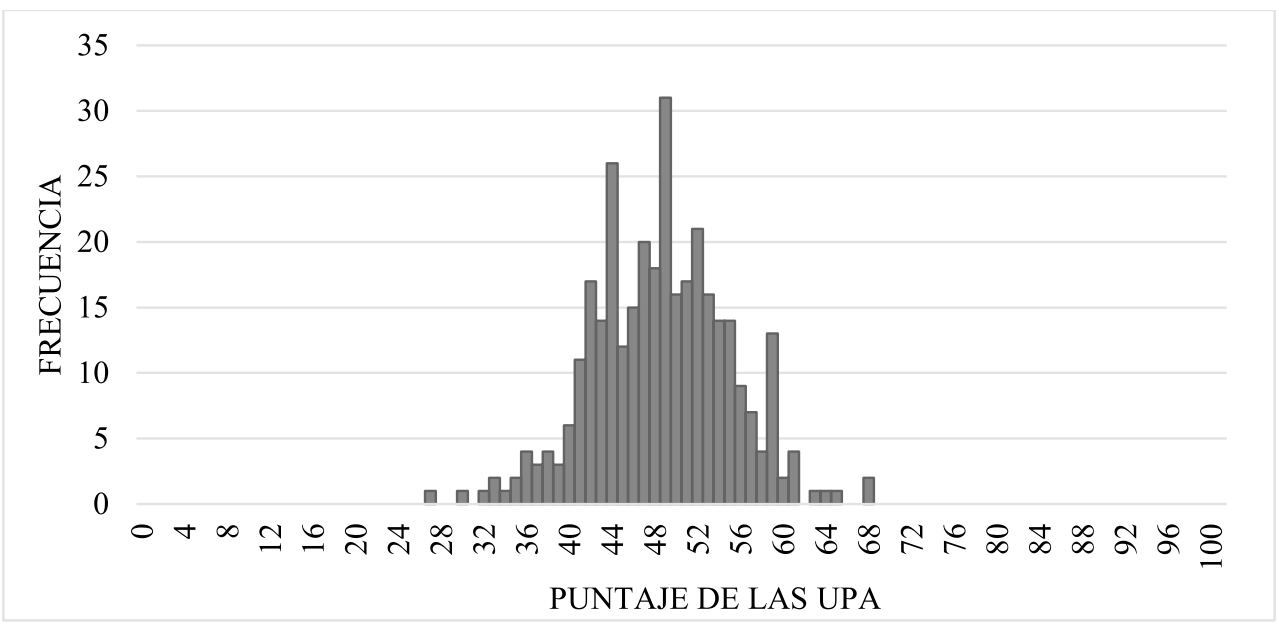

Figura 1. Distribución del IMDS de las UPA palmicultoras de Norte de Santander.

Fuente: elaboración propia con base en DANE-3.er CNA (2014).

Por otra parte, en la escala de valoración cualitativa el índice resalta que la actividad se lleva a cabo en escenarios con bajos niveles de desarrollo sostenible para Norte de Santander; en primer lugar, porque ninguna de las UPA pal- micultoras en todo el departamento obtuvo un IMDS alto, tal como lo detalla la Figura 2; y, en segundo lugar, porque gran parte de las UPA se concentran en desempeños bajos (62.3\%).

3 El intervalo se construyó teniendo en cuenta el resultado promedio más y menos una desviación estándar. 


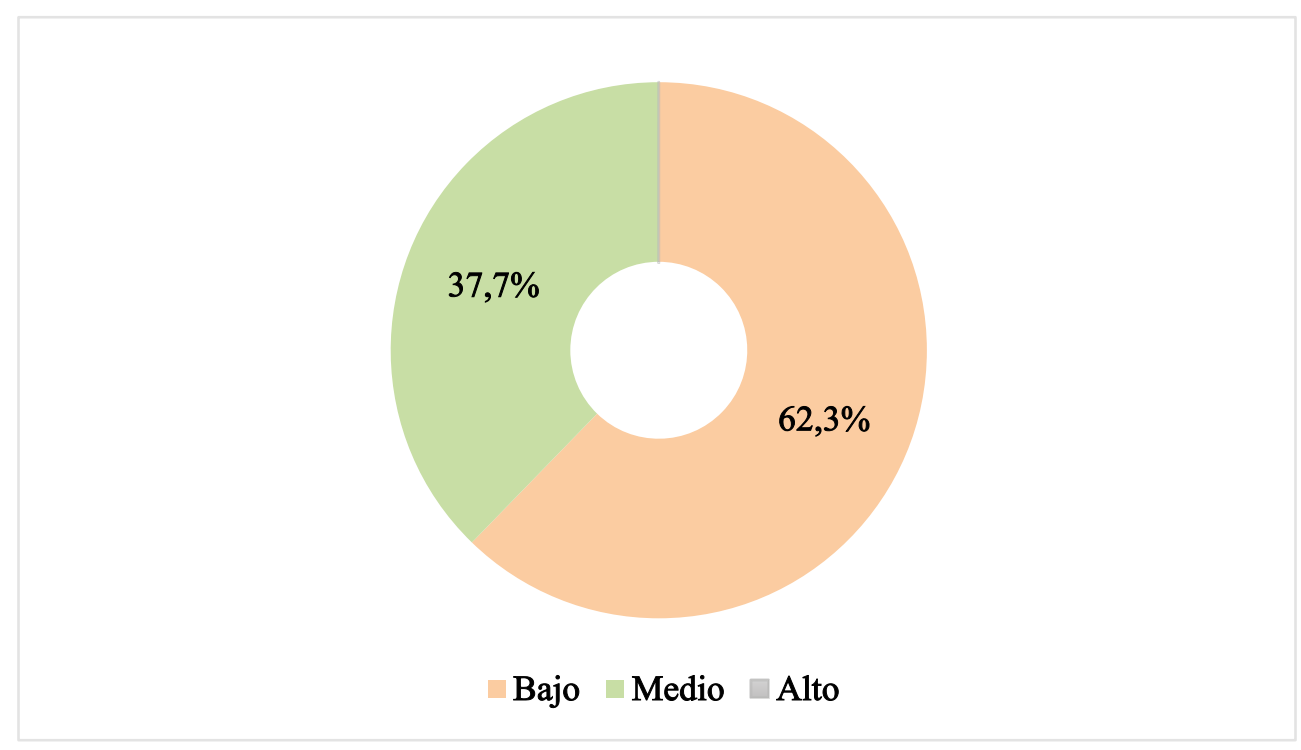

Figura 2. Resultados cualitativos del IMDS de las UPA palmicultoras de Norte de Santander.

Fuente: elaboración propia con base en DANE 3.er CNA (2014).

Los anteriores resultados reflejan los bajos desempeños de la mayoría de las UPA palmicultoras del departamento, lo cual sugiere a grandes rasgos que la actividad del cultivo agroindustrial de palma de aceite no parece ofrecer condiciones que promuevan un desarrollo con crecimiento económico próspero, que sean socialmente incluyentes y ambientalmente sostenibles en el marco de la buena gobernanza; es decir, la actividad no promueve integralmente el desarrollo sostenible para los palmicultores de Norte de Santander. De ahí la necesidad de identificar en qué dimensiones se encuentran las mayores debilidades, lo cual se aborda a continuación.

\section{Desempeño del IMDS por dimensión}

La desagregación del IMDS por dimensiones permite apreciar de forma más detallada los resultados, esto es, captar qué dimensiones en particular inciden sobre el resultado global. La Figura 3 detalla los resultados por dimensión, diferenciando el desempeño positivo (puntaje calculado de la dimensión en el IMDS) y el desempeño normativo (máxima calificación posible 100 puntos en cada dimensión), lo cual indica que dicha dimensión ofrece un escenario ampliamente favorable para los propósitos del desarrollo sostenible. 


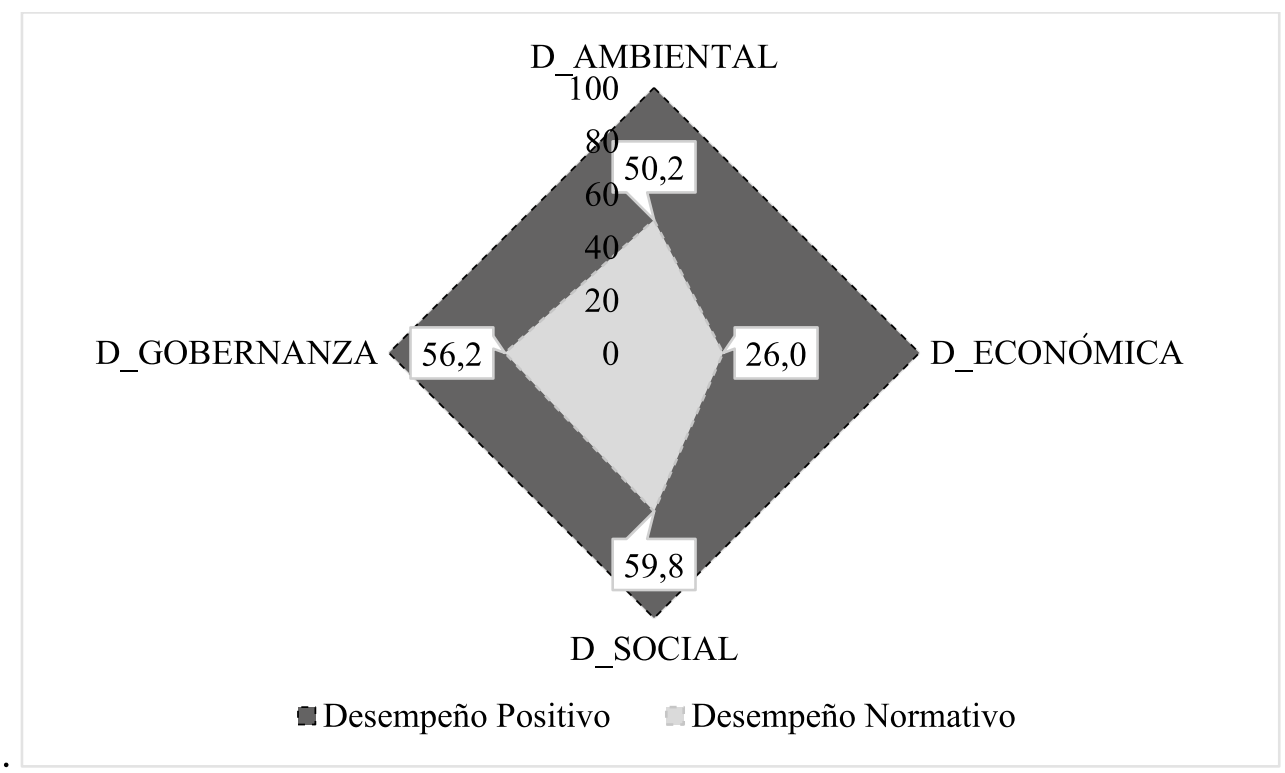

Figura 3. Desempeño por cada dimensión del desarrollo sostenible de las UPA palmicultoras de Norte de Santander.

Fuente: elaboración propia con base en DANE 3.er CNA (2014).

La figura anterior evidencia que la dimensión en la cual las UPA palmicultoras del departamento obtienen el mejor resultado es la de inclusión social con un puntaje de 59,8 puntos. Dicho resultado sugiere que la mayoría de las palmicultoras poseen ciertas condiciones sociales que fortalecen el desarrollo sostenible. Analizando las variables que componen la dimensión social, se encuentra que la cobertura en salud es una variable que incide significativamente sobre el desempeño de la dimensión, como se observa en la Figura 4, seguida de condiciones de la vivienda, pues como se expresó en la caracterización, la gran mayoría de los palmicultores tiene acceso a atención médica básica; asimismo, la mayoría de las viviendas no se encuentran en privación por condiciones como las paredes y pisos, lo cual indica que las palmicultoras disponen de ciertos aspectos necesarios para una vida digna. 


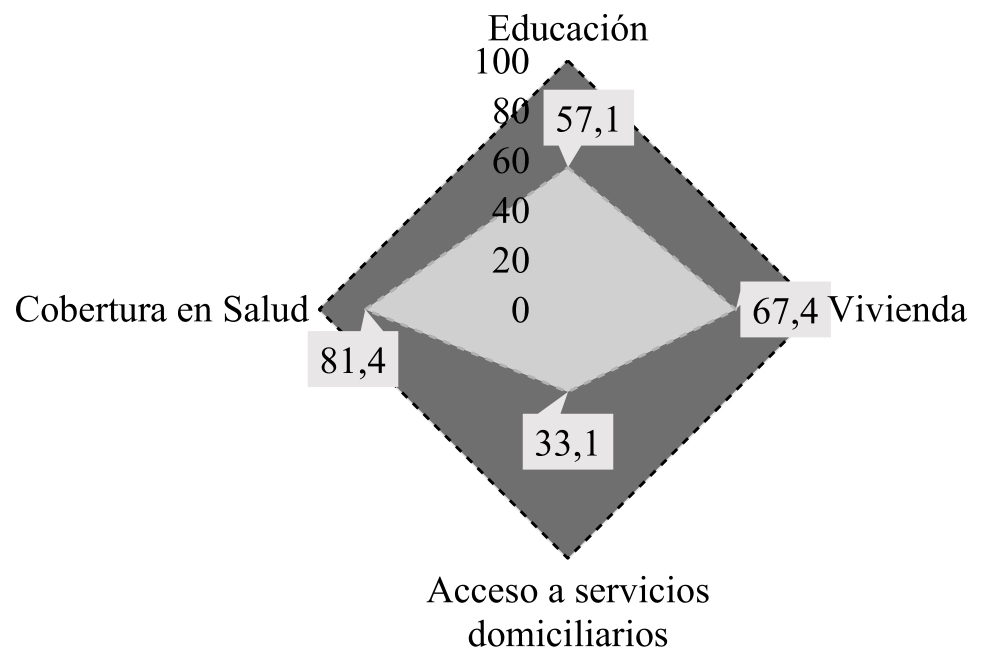

aDesempeño Normativo Desempeño Positivo

Figura 4. IMDS, dimensión inclusión social de las UPA palmicultoras de Norte de Santander.

Fuente: elaboración propia con base en DANE 3.er CNA (2014).

No obstante, los resultados en las demás variables de la dimensión de inclusión social son algo dispersos. En el caso de la educación, presenta unos resultados promedio, presionados positivamente por la alfabetización y negativamente por el logro educativo promedio. Respecto al acceso a servicios domiciliarios, es la variable que jalona a la baja la dimensión de inclusión social, dado que la mayoría de las palmicultoras no cuentan con servicios domiciliarios como alcantarillado o acueducto.
Por otra parte, la segunda dimensión de mayor calificación es la dimensión de gobernanza (56,2 puntos), donde se presenta que la variable de mejor desempeño es el vínculo con el mercado, pues todas las UPA manifestaron acceso al sistema financiero. Frente al papel del Gobierno, el mejor resultado lo obtiene la inexistencia de dificultades para acceder al agua por parte de instituciones, personas particulares o por falta de infraestructura; sin embargo, las UPA palmicultoras claramente no han logrado construir un capital social sólido, debido a su escasa participación en actividades de trabajo colectivo (ver Figura 5). 


\section{Papel del Gobierno}

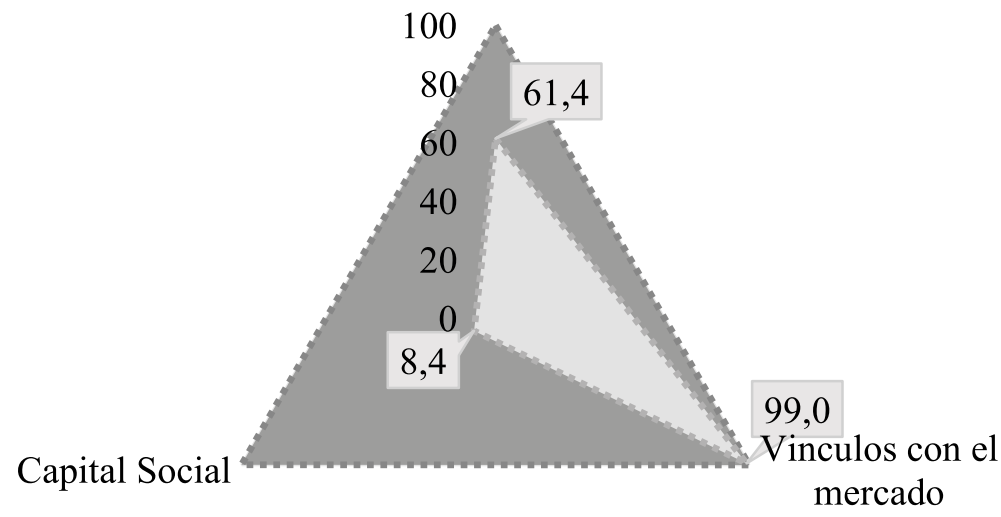

thesempeño Normativo Desempeño Positivo

Figura 5. Desempeño de la dimensión de gobernanza de las UPA palmicultoras de Norte de Santander.

Fuente: elaboración propia con base en DANE 3.er CNA (2014).

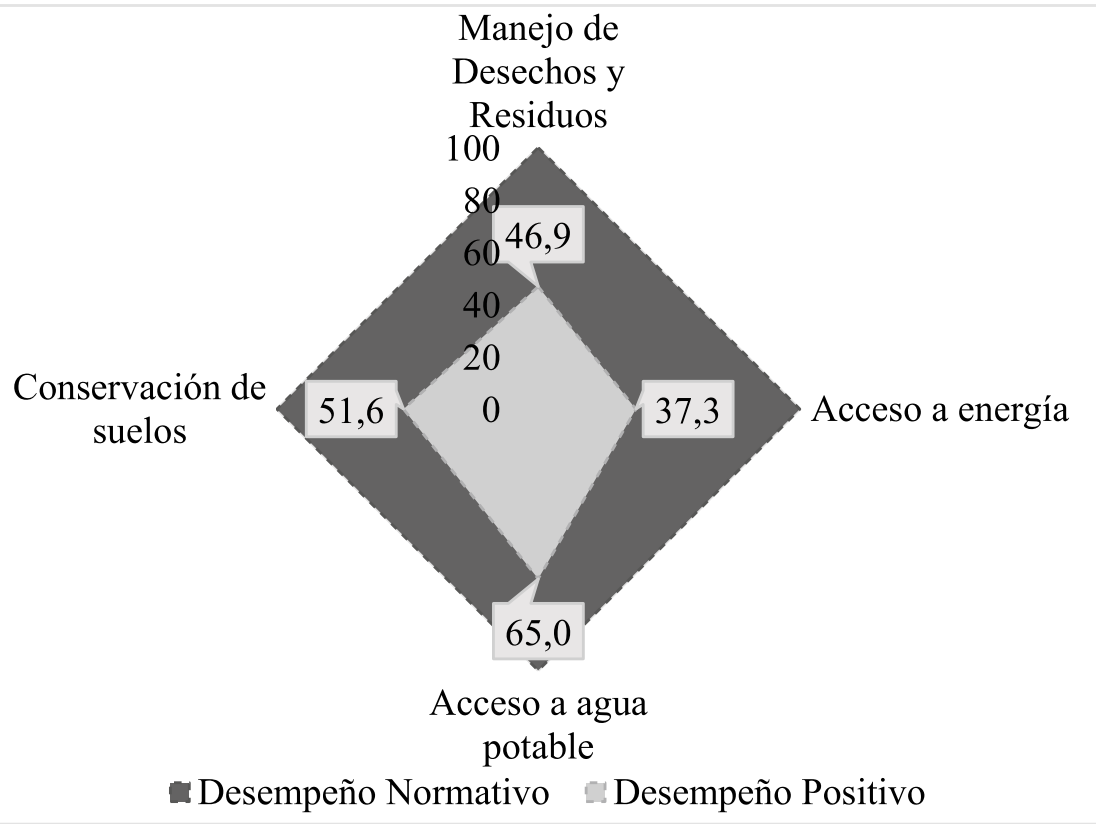

Figura 6. Desempeño de la dimensión ambiental de las UPA palmicultoras de Norte de Santander.

Fuente: elaboración propia con base en DANE 3.er CNA (2014). 
En el caso de la dimensión ambiental, la cual obtuvo 50,2 puntos, el desempeño más favorable se presentó en la protección de las fuentes naturales de agua y en el sistema de riego utilizado. Pero es preocupante el manejo y la reutilización de desechos tanto animales y vegetales como de plástico, vidrio o PVC, dado que la mayoría de las UPA realizan prácticas poco amigables con el medio ambiente, por lo cual, es esta variable la que jalona negativamente la dimensión (ver Figura 6).
Por su parte, la dimensión económica no arroja resultados muy provechosos para el desarrollo sostenible de las UPA palmicultoras de Norte de Santander. Su desempeño se ve afectado especialmente por la escasa presencia de infraestructura y tecnología moderna que permita mejorar los niveles de productividad. Sin embargo, presenta resultados más alentadores en términos de producción, pues un número significativo de UPA presenta un favorable rendimiento por hectárea. Asimismo, el tamaño de la UPA en términos del empleo incide positivamente sobre la dimensión (ver Figura 7).

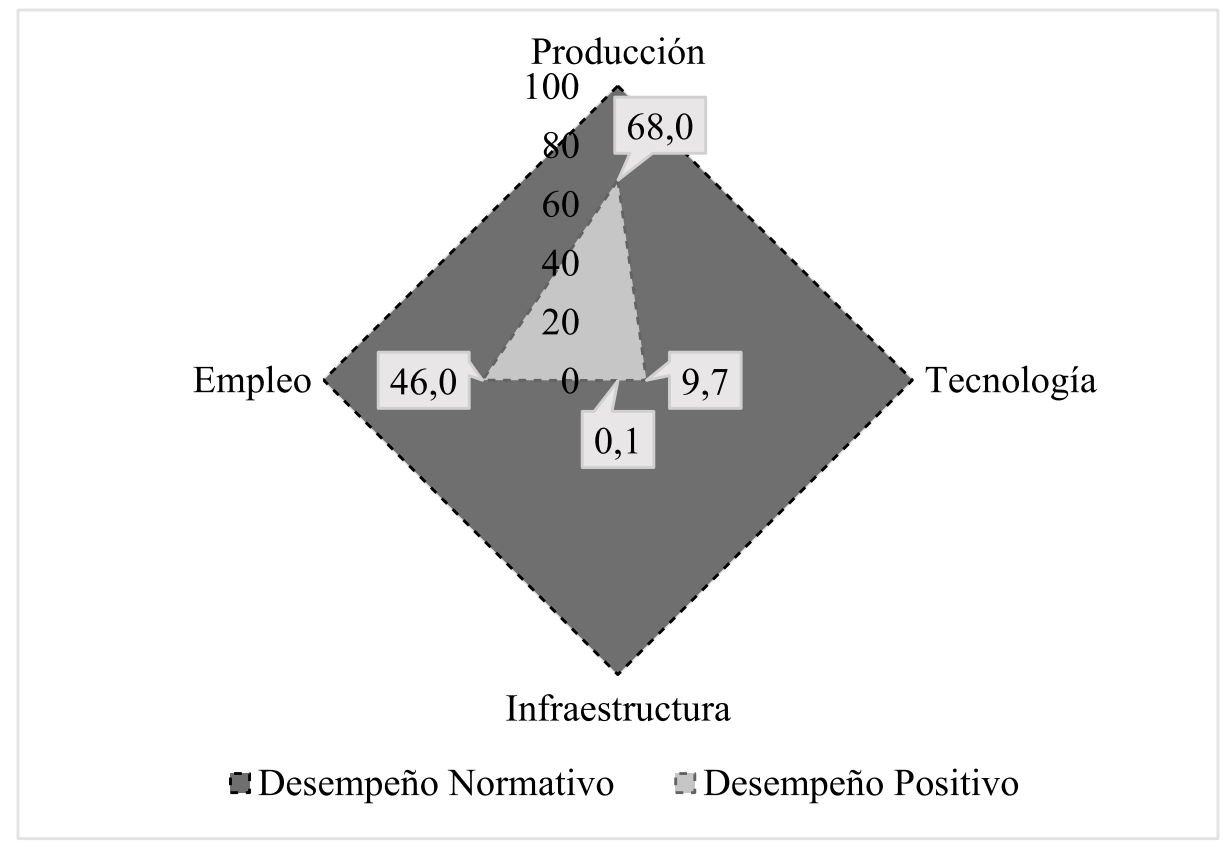

Figura 7. Desempeño de la dimensión económica de las UPA palmicultoras de Norte de Santander.

Fuente: elaboración propia con base en DANE 3.er CNA (2014). 


\section{DISCUSIÓN}

Los hallazgos más críticos para el sector palmicultor están relacionados con el desempeño económico, en donde se destaca la escasa presencia de infraestructura y tecnología moderna que permitan mejorar los niveles de productividad de la actividad. En este sentido, es preciso tener en cuenta que el tamaño de la UPA es una factor influyente en las decisiones de inversión de infraestructura y tecnología, dada la posibilidad de producir a gran escala con mayores rendimientos. Pero en Norte de Santander, pese a que el tamaño promedio de UPA palmicultoras (31,3 hectáreas) se encuentra por encima del promedio de las demás actividades agrícolas del departamento, está por debajo del tamaño promedio entre los cinco principales departamentos productores $^{4}$ (44,7 hectáreas). Tal como lo exponen Pertuz y Santamaría (2014), la actividad palmicultora es sostenible económicamente para el gran empresario, dada la productividad y rentabilidad del cultivo. Lo anterior significa una desventaja para los productores de mediana y pequeña escala.

Ahora bien, en consonancia con lo anterior, diversos estudios del sector señalan los escasos beneficios económicos de los que disfrutan los pequeños y medianos productores frente a los grandes; no obstante, existen efectos positivos, dadas determinadas condiciones en el mercado financiero (precio del crédito) que pueden incentivar la asociatividad de los pequeños y medianos palmicultores, y potencializar el crecimiento del monocultivo, lo cual mejora la sostenibilidad económica de estos; este resultado, aunque favorable, se obtuvo del estudio realizado por el Instituto Alexander von Humboldt (2000), en el que se demostró, por el contrario, lo perverso que podría ser para la biodiversidad y la conservación de ecosistemas el Incentivo de Capitalización Rural (ICR).

Por otra parte, dentro de las dinámicas del sector palmicultor en Norte de Santander resalta la escasa mecanización del proceso productivo, si se tiene en cuenta que el $68.9 \%$ manifestó no utilizar ninguna de las herramientas más básicas para su actividad. No obstante, frente a la mecanización es preciso considerar que esta va mucho más allá de la inclusión de nueva maquinaria, ya que implica incorporar los nuevos avances tecnológicos en pro de la productividad de la actividad, con iniciativas de agricultura de precisión, como la planteada por Lizarazo y Alfonso (2011), la cual está basada en el reconocimiento de la variabilidad espacial y temporal del clima, los suelos y los cultivos, y consecuentemente, de la importancia de proporcionar un manejo agronómico específico que atienda esas diferencias.

En este sentido, vale la pena resaltar los planteamientos de la Organización de las Naciones Unidas para la

$4 \quad$ Meta, Cesar, Casanare, Santander y Magdalena. 
Alimentación y la Agricultura (ONUAA, 2018) acerca de alcanzar las metas establecidas en los ODS 2030. En ellos se advierte que es crucial mejorar la productividad, si se pretende transformar los medios de subsistencia de cientos de millones de personas en todo el mundo, dado que muchos pequeños agricultores familiares siguen sin poder acceder a los recursos y a los servicios necesarios. De manera que, si no se cuenta con tecnologías e infraestructura rural, los principales productores de alimentos del mundo no pueden participar completamente de la economía (ONUAA, 2018).

Otros estudios, como el de Ramírez (2012), sugieren que, por el contrario, la palmicultura no es una gran generadora de empleo como comúnmente se cree. En ella, la flexibilización laboral es el mecanismo para hacer competitivo al sector, mediante la creación de cooperativas laborales que reduzcan los costos relacionados con el trabajo y que arrojen como resultados beneficios y sostenibilidad económica; pero esto ocurre solo en el caso de las grandes plantaciones, como se presenta en el Magdalena Medio y otras regiones del país: sumado a esto, se observa que en la contratación para el cultivo existen situaciones que limitan no solo la productividad y, por ende, las posibilidades de mejorar los ingresos para los agricultores, sino que también interponen obstáculos al acceso de la mujer en el mercado laboral del sector; situación que amplía la brecha laboral entre hombres y mujeres, pues como lo manifiestan Zambrano et al. (2019), pese a que en el cultivo de palma en Norte de Santander los empleos del cultivo son formales y calificados, según las entrevistas a los directores del gremio en la región, estos empleos no están certificados, y la contratación suele incluir mayormente a hombres tanto en el cultivo como en la transformación de la cosecha.

En cuanto a los resultados sociales, la presente investigación identificó debilidades en el logro educativo de quienes habitan las UPA cañicultoras, como también en el acceso a los servicios públicos de acueducto y alcantarillado. $\mathrm{Y}$ a esto se suman otros fenómenos sociales -que la literatura ha denunciado y que no deben ser ignorados-, los cuales se han manifestado paralelamente en el país por la implementación y expansión de los cultivos de palma africana, en los que hay varios casos de campesinos desplazados (en particular afrodescendientes) y despojados de sus tierras para establecer el cultivo de grandes extensiones. Esto se presenta en múltiples regiones del país y en el marco del conflicto armado, en el que han participado conjuntamente el sector empresarial y grupos paramilitares (Fundación Ideas para la Paz, 2011). Hay que destacar que este fenómeno se produce por la expansión y los posicionamientos de estos grupos armados ilegales, que compiten con las guerrillas por el control del territorio (García, 2014). 
Respecto a los resultados en términos ambientales, es preciso tener en cuenta que solo el $65.9 \%$ de los palmicultores manifestaron realizar alguna práctica de conservación del suelo, aunque esta ha sido identificada como una muy buena práctica para mejorar el rendimiento del cultivo. En este punto es importante citar a Hai (2000), quien recomienda la utilización de coberturas de leguminosas para la protección del suelo y la mejora de la fertilidad.

Como se mencionó, el estudio del Instituto Alexander von Humboldt (2000) arroja evidencia de las diversas afectaciones sobre la biodiversidad del cultivo de palma africana. Por ejemplo, el cultivo se establece en lugares en los que se requiere la deforestación de bosque primario o nativo, lo que sustituye ecosistemas naturales con implicaciones sobre la biodiversidad que se manifiestan en destrucción de especies de flora y fauna. El estudio también señala que la conservación de la biodiversidad y la producción de aceite son excluyentes o que van en contravía, en donde la planificación es crucial. Las afectaciones ambientales no se gestan exclusivamente en la expansión de los cultivos, sino también en el cultivo en sí y en el procesamiento en planta; por ejemplo, el uso intensivo de agroquímicos termina degradando los suelos y sobreexplotando los recursos hídricos (Coviello et al., 2008).

Finalmente, en cuanto a la dimensión de la gobernanza, el gremio ha logrado contar con políticas de varios gobiernos de orden nacional y departamental que han promovido la expansión y el fortalecimiento del cultivo; en otras palabras, existe una articulación entre palmicultores e instituciones públicas. Por otra parte, la existencia de organizaciones como Fedepalma y Corporación Centro de Investigación en Palma de Aceite (Cenipalma) son evidencia de esfuerzos por armonizar la producción a nivel nacional y dinamizar la actividad. Esto se refuerza con uno de los hallazgos de la investigación, en donde más del $52 \%$ de las UPA palmicultoras señalan pertenecer a algún gremio u organización relacionada con la actividad. Esto, ciertamente, es uno de los fuertes del gremio; no obstante, nuevamente estos escenarios tiene un alcance limitado, si se tiene en cuenta que son los pequeños y medianos palmicultores los que en menor medida logran acceder a los beneficios, pues no están asociados; por ejemplo, se observa que un poco más del $64 \%$ no recibió asesoría en temas de acceso financiero, frente a un $94 \%$ que solicitó un crédito.

Considerando lo anterior, es necesario resaltar el papel fundamental de los productores agrícolas en el desarrollo de la actividad palmicultora. Tal como lo plantean Rizo-Mustelier et al. (2017), la utilización de los saberes campesinos es vital, puesto que las culturas campesinas de todas las latitudes han aplicado históricamente prácticas ecológicas y respetuosas de la naturaleza, son las menos consumistas y dependen muy poco de los insumos externos, por lo cual es un reto potenciar la agencia de 
los campesinos en pro de lograr una producción de palma sostenible económica, social y ambientalmente.

\section{CONCLUSIONES}

La palma de aceite es un producto agrícola de gran importancia para Norte de Santander, pues es el tercero de mayor siembra en el departamento, después del arroz y el café; sin embargo, presenta un rendimiento promedio bajo en comparación con el resto de los departamentos productores. Es de resaltar que el cultivo de la palma no es una actividad que se realice a pequeña escala, puesto que el área sembrada promedio por UPA está por encima del resto de los productos agrícolas, no obstante, sigue siendo un área menor que el promedio de los cinco departamentos con mayor producción. Asimismo, respecto al uso de tecnologías e infraestructura se evidencia la escasa tecnificación del cultivo de palma y una significativa falta de adecuación del predio para el cultivo. Por otra parte, un aspecto de gran relevancia en el desempeño económico de una actividad es la capacidad de generar empleo y, en promedio, cada UPA genera aproximadamente tres empleos permanentes.

En términos de inclusión social, un aspecto positivo de la actividad palmicultora está relacionado con la asistencia escolar, pero el logro educativo promedio es bastante bajo y el analfabetismo sigue muy presente. Ahora, en cuanto a las características de la vivienda relacionadas con las condiciones mate- riales, la mayor privación se encuentra en el material predominante de los pisos y en el acceso a los servicios, y la mayor dificultad está en alcantarillado y acueducto. Frente al acceso a salud, aunque hay cobertura, persiste la brecha respecto a las coberturas urbanas.

En lo relativo al impacto ambiental de las UPA palmicultoras, resalta el escaso manejo de desechos orgánicos, así como la quema o entierre como práctica fuertemente utilizada para el manejo de los residuos inorgánicos, a pesar de ser altamente contaminante; de igual manera, las UPA palmicultoras usan energías como combustible, carbón mineral, tracción y transporte animal o no usan ninguna fuente de energía, lo cual es desfavorable tanto en términos ambientales como en términos de la eficiencia energética. Por otra parte, se percibe el interés de los palmicultores por cuidar o proteger las fuentes naturales del recurso hídrico, por conservar sus suelos y realizar controles de plagas, como control orgánico, manual, mecanizado y biológico, que no son tan nocivos para el medio ambiente.

Con relación a la gobernanza, pese a que la actividad cuenta con un gremio a nivel nacional (Fedepalma), los resultados señalan que solo uno de cada dos palmicultores pertenecen a alguna cooperativa, gremio o asociación. Asimismo, es escaso el trabajo colectivo, lo que dificulta la posibilidad de ampliar la capacidad productiva. No obstante, se evidencia 
el fuerte apalancamiento financiero que ha tenido la actividad, dado que en su totalidad los palmicultores han acudido al sistema financiero y el $97.9 \%$ reportó créditos aprobados.

En cuanto a la estimación del IMDS, la distribución, calificación y desempeño de las más de 330 UPA palmicultoras en el departamento sugieren un escenario complejo para el alcance sinérgico del desarrollo sostenible, toda vez que, la mayor parte de las UPA se ubicaron en calificaciones del IMDS en el rango bajo-medio, y de igual forma, la mayoría obtuvo una calificación baja, sin olvidar que ninguna logró alcanzar una calificación alta. En cuanto al desempeño, la de menor desempeño fue la dimensión económica, seguida de la dimensión ambiental, gobernanza y social. Este resultado está en consonancia con el encuentro común de gran parte de la literatura que sugiere que las grandes plantaciones son las que logran la sostenibilidad económica dada su capacidad de levantar infraestructura y adquirir tecnología, y estas variables son precisamente aquellas de las que carecen las UPA del departamento.

En ese mismo orden de ideas, la segunda calificación más baja corresponde a la dimensión ambiental, cuyos resultados nuevamente coinciden con lo expresado por parte de la literatura, en donde la actividad presenta importantes efectos sobre los ecosistemas y la biodiversidad; no obstante, la baja calificación en la presente investigación gira en torno a otras variables como manejo de recursos y residuos por parte de los palmicultores, más que al ejercicio empírico del cultivo. De igual forma, el desempeño en la dimensión de la gobernanza concuerda con lo mencionado en la sección de discusión en relación con otras investigaciones; por ejemplo, los vínculos con el mercado (mercado financiero) como el trabajo articulado con los gobiernos e instituciones es significativo, pero no sucede igual en cuanto al capital social, porque aunque el $52.1 \%$ pertenece a algún tipo de asociación u organización, casi la totalidad de las UPA no realizan trabajo colectivo. Hay que mencionar que esta es una diferencia relevante frente a los demás hallazgos de otras investigaciones.

Ahora bien, la dimensión social obtuvo el mejor desempeño, lo cual es curioso, dado que la literatura comenta el bajo acceso a beneficios económicos y sociales de gran parte de los palmicultores. Para el caso de la presente investigación, es preciso contextualizar estos resultados en Colombia y Norte de Santander, toda vez que varias plantaciones se ubican en zonas con presencia de grupos armados irregulares y en conflicto armado, a lo que se suma la escasa presencia del Estado, situaciones que han limitado el mejoramiento de estas variables; por tanto, aunque dichos resultados no corresponden en particular al cultivo de la palma africana, sus dinámicas sí pueden estar relacionadas en cuanto a expansión y ubicación. 
En síntesis, los hallazgos del presente artículo develan los bajos desempeños de la mayoría de las UPA palmicultoras del departamento, lo cual sugiere a grandes rasgos que la actividad del cultivo agroindustrial de palma de aceite no parece ofrecer condiciones que promuevan un desarrollo con crecimiento económico próspero, socialmente incluyente y ambientalmente sostenible en el marco de la buena gobernanza; es decir, la actividad no promueve integralmente el desarrollo sostenible para los palmicultores de Norte de Santander.

Finalmente, es importante tener en cuenta que a pesar de que el palmicultor es un sector clave en el departamento, en materia de desarrollo sostenible tiene problemas que solucionar, sobre todo la necesidad de mejorar la transformación productiva por medio del cambio tecnológico, no solo en la dimensión económica (productividad), sino en el uso de energías alternativas a través de la innovación. Lo que exige una mayor sinergia con el contexto socioeconómico para mejorar la inclusión social por medio del capital humano y la política pública en dos sentidos: por un lado, un paquete de incentivos que fortalezcan el capital social para mejorar los procesos asociativos y beneficiarse de las políticas de fomento al desarrollo agroindustrial del sector, y por otro, la provisión de bienes públicos que reduzcan las brechas sociales y, a la vez, eleven la calidad de vida, condiciones necesarias en un contexto que aspira a cumplir los ODS.

\section{AGRADECIMIENTOS}

A la Gobernación de Norte de Santander, al Grupo de Investigación de Ciencias Económicas y Empresariales (GICEE) y al Programa de Economía de la Universidad de Pamplona; de igual forma, al Grupo de Investigación Competitividad y Sostenibilidad para el Desarrollo de la Universidad Libre, seccional Cúcuta.

\section{FINANCIAMIENTO}

El presente artículo es producto de la Convocatoria para la Formación de Capital Humano de Alto Nivel en el departamento de Norte de Santander 2016 (Maestría Nacional 753), de la cual los autores fueron beneficiarios (Jazmín Manzano y Alexander Botello); asimismo, hace parte de la investigación sobre el desarrollo sostenible de la agricultura nortesantandereana 2019 inscrita al Grupo de Investigación de Ciencias Económicas y Empresariales (GICEE), que fue aprobada en la convocatoria interna del Banco de Proyectos 2019 de la Universidad de Pamplona. Finalmente, es resultado del proyecto de investigación interinstitucional con el Grupo de Investigación Competitividad y Sostenibilidad para el Desarrollo de la Universidad Libre Seccional Cúcuta, con el líder del Grupo Mario de Jesús Zambrano Miranda. 


\section{DECLARACIÓN DE CONFLICTOS} DE INTERESES

Los autores declaran que los resultados del presente artículo fueron interpretados de forma objetiva y en ninguna circunstancia tienen como fin apoyar o perjudicar a ninguna institución en particular; por tanto, los hallazgos no representan conflicto de intereses con las instituciones donde trabajan los autores como tampoco con la Revista Apuntes del CENES.

\section{CONTRIBUCIÓN DE LOS AUTORES}

Los autores colaboraron en la elaboración de todo el documento; sin embargo, su contribución se dio en mayor medida en algunas secciones, como por ejemplo, Mario Zambrano en antecedentes y marco teórico, Jazmín Manzano y Alexander Botello en metodología y procesamiento de datos, y finalmente los tres autores contribuyeron en el análisis de resultados, la discusión y las conclusiones. 


\section{REFERENCIAS}

[1] Arias, F. (2006). Desarrollo sostenible y sus indicadores. Revista Sociedad y Economía, (11), 200-229.

[2] Bourguignon, F. (2017). La globalización de la desigualdad. Fondo de Cultura Económica.

[3] Brown, L. (Dir). (1996). La situación del mundo 1996: Informe anual del World Watch Institute sobre medio ambiente y desarrollo. Icaria.

[4] Carrizosa, J. (1996). La evolución del debate sobre el desarrollo sostenible. En Corporación Ecofondo (Ed.), La gallina de los huevos de oro: debate sobre el concepto de desarrollo sostenible, (pp. 44-68). CEREC.

[5] Correa, F. (2017). Desarrollo sostenible: revisión teórica desde la economía. Ediciones UNAULA.

[6] Coviello, M., Gómez, J., Razo, C. \& Rodríguez, A. (2008). Biocombustibles líquidos para transporte en América Latina y el Caribe. CEPAL.

[7] Daly, H., \& Coob, J. (1989). For the Common Good: Redirecting the Economy Toward Community, the Environment, and a Sustainable Future. Beacon Press.

[8] Departamento Administrativo Nacional de Estadística -DANE-. (2014). Tercer Censo Nacional Agropecuario. https://www.dane.gov.co/index.php/ estadisticas-por-tema/agropecuario/censo-nacional-agropecuario-2014

[9] Departamento Administrativo Nacional de Estadística -DANE-. (2018). Censo Nacional de Población y Vivienda. https://www.dane. gov.co/index.php/estadisticas-por-tema/demografia-y-poblacion/ censo-nacional-de-poblacion-y-vivenda-2018

[10] Dixon, J. \& Fallon, L. (1991). El concepto de la sostenibilidad: sus orígenes, alcances y utilidad en la formulación de políticas ambientales. En J. Vial (comp.), Desarrollo y medio ambiente. Hacia un enfoque integrador. CIEPLAN.

[11] Federación Nacional de Cultivadores de Palma de Aceite -Fedepalma-. (s.f). La palma de aceite en el departamento de Norte de Santander. https://web.fedepalma. org/sites/default/files/files/infografia_norte_santander.pdf 
[12] Fundación Ideas para la Paz. (2011). Sector privado y desplazamiento forzado interno (DFI) en Colombia. Working Papers 8. http://www.ideaspaz.org/ publications/posts/96

[13] Gallopín, G. (2003). Sostenibilidad y desarrollo sostenible. CEPAL.

[14] García, P. (2014). Tierra, palma africana y conflicto armado en el Bajo Atrato chocoano, Colombia. Una lectura desde el cambio en los órdenes de extracción. Estudios Socio-Jurídicos, 16(1), 207-242. https://doi.org/10.12804/ esj16.1.2014.05

[15] Gobernación de Norte de Santander. (2016). Plan de desarrollo departamental (2016-2019): un norte productivo para todos. http://www.sednortedesantander.gov. co/sitio/images/documentos/informesdelsector/PDD\%20NDS\%202016-2019.pdf

[16] Hai, T. (2000). Land Use and the Oil Palm Industry in Malaysia. WWF.

[17] Hidalgo-Capitán, A. (2011). Economía política del desarrollo: La construcción retrospectiva de una especialidad académica. Revista de Economía Mundial, (28), 279-320.

[18] Instituto Alexander von Humboldt. (2000). Biosintesis 21-Incentivos económicos perversos para la conservación de la biodiversidad: el caso de la palma africana. http://repository.humboldt.org.co/handle/20.500.11761/32637

[19] Jacobs, M. (1991). Economía verde. Tercer Mundo.

[20] Lizarazo, I. \& Alfonso, O. (2011). Aplicaciones de la agricultura de precisión en palma de aceite "Elaeis Guineensis" e híbrido O x G. Revista de Ingeniería, (33), 124-130. http://dx.doi.org/10.16924\%2Friua.v0i33.185

[21] Organización de las Naciones Unidas para la Alimentación y la Agricultura -ONUAA-. (2018). Transformar la alimentación y la agricultura para alcanzar los ODS. http://www.fao.org/3/i9900es/i9900es.pdf

[22] Pertuz, A. \& Santamaría, A. (2014). La palmicultura colombiana: sostenibilidad económica, social y ambiental. Tendencias, 15(1), 173-186. https://doi.org/10.22267/ rtend. 141501.55

[23] Quiroga, R. (2007). Indicadores ambientales y de desarrollo sostenible: avances y perspectivas para América Latina y el Caribe. CEPAL. 
[24] Ramírez, R. (2012). Diagnóstico situación de las y los trabajadores de la agroindustria de la palma en el Magdalena Medio y Meta. FENSUAGRO.

[25] Rizo-Mustelier, M., Vuelta-Lorenzo, D. \& Lorenzo-García, A. (2017). Agricultura, desarrollo sostenible, medioambiente, saber campesino y universidad. Ciencia en su PC, (2), 106-120.

[26] Sachs, J. (2014). La era del desarrollo sostenible. Paidós.

[27] Sachs, W. (1996). La anatomía política del desarrollo sostenible. En Corporación Ecofondo (ed.), La gallina de los huevos de oro: debate sobre el concepto de desarrollo sostenible, (pp. 15-43). CEREC.

[28] Sanjuán, J. \& Moreno, N. (2010). Aplicación de insumos biológicos: una oportunidad para la agricultura sostenible y amigable con el medioambiente. Revista Colombiana de Biotecnología, 12(1), 4-7.

[29] Sen, A. (2000). Desarrollo y libertad. Planeta.

[30] Wackernagel, M., \& Rees, W. (1997). Perceptual and Structural Barriers to Investing in Natural Capital: Economics From an Ecological Footprint Perspective. Ecological Economics, 20(1), 3-24. https://doi.org/10.1016/ S0921-8009(96)00077-8

[31] Xercavins, J., Cayuela, D., Cervantes, G. \& Sabater, A. (2005). Desarrollo sostenible. Universitat Politècnica de Catalunya.

[32] Zambrano, M., Manzano J., Castro, K., Botello, E., Ramírez, J., Delgado, E. $\&$ Pacheco, C. (2019). Agroindustria Norte de Santander: Universidad Libre, Seccional Cúcuta. 